\title{
Engineering UiO-66 Metal Organic Framework for Heterogeneous Catalysis
}

Prof. Dr. Amarajothi Dhakshinamoorthy ${ }^{* a}$ Dr. Andrea Santiago-Portillo, ${ }^{\mathrm{b}}$ Prof. Dr. Abdullah M. Asiri, ${ }^{c}$ and Prof. Dr. Hermenegildo Garcia ${ }^{* b, c}$

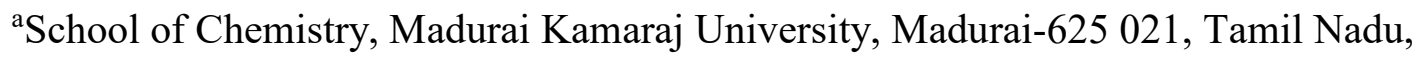
India. E-mail: admguru@gmail.com

${ }^{b}$ Departamento de Quimica and Instituto Universitario de Tecnologia Quimica (CSIC-UPV), Av. De los Naranjos s/n, 46022 Valencia, Spain. E-mail: hgarcia@qim.upv.es ${ }^{\mathrm{c}}$ Centre of Excellence for Advanced Materials Research, King Abdulaziz University, Jeddah, Saudi Arabia.

\begin{abstract}
Metal organic frameworks (MOFs) are currently attracting considerable attention as heterogeneous catalysts at moderate temperatures, mainly for liquid-phase reactions. Since structural stability is one of the major concerns for the use of MOFs in catalysis, particularly considering that frequently some of the reported MOF materials are very unstable, the interest in this area has been focused on those MOFs exhibiting the highest structural robustness, UiO66 being among the most widely used. Two introductory sections deal with the synthesis, structure and main properties of UiO-66, including its remarkable thermal (up to $350{ }^{\circ} \mathrm{C}$ ) and chemical (aqueous solution in a wide $\mathrm{pH}$ range) stability. The main body of the review summarizes those examples of using UiO-66 in catalysis grouped according to the nature of the active sites, starting with the use of UiO-66 as Lewis acids. In this section, emphasis has been made in the recent procedures to generate in a controlled way structural defects that generate Lewis acidity. Other sections cover examples illustrating substituted terephthalate as active sites and the evidence that there is a synergy between acid and basic sites in close proximity that make some of these UiO-66 with substituents at the linker to act as dual acidbase catalysts. Other sections are focused on the use of UiO-66 as hosts of metal nanoparticles, metal oxides and other host, remarking the influence that the nature of UiO-66 and the possible presence of substituents in the framework play on the activity of the incorporated guest. The last section summarizes the current state of the art in the use of UiO-66 in catalysis and provides our views on future developments regarding the application of UiO-66 in industrial processes.
\end{abstract}




\section{Contents}

1. Introduction

1.1 Structure and properties of UiO-66

1.2 Synthesis of UiO-66

2. Scope and concept of the review

3. Metal nodes as active sites

3.1 Nodes as Lewis acids

3.2 Nodes as redox sites

4. Functionalized BDC in UiO-66

4.1 $\mathrm{UiO}-66-\mathrm{SO}_{3} \mathrm{H}$ as solid acid

4.2 $\mathrm{UiO}-66-\mathrm{NH}_{2}$ in catalysis

4.3 Other functionalized BDC as catalysts

5. UiO-66 as host

5.1 Pt NPs

5.2 Pd NPs

5.3 Cu NPs

5.4 Other metal NPs

6. Conclusions 


\section{Introduction}

Molecular metal complexes had been continuously used as homogeneous catalysts ${ }^{[1]}$ to promote a large diversity of reactions including Lewis acid catalyzed and redox processes. Not surprisingly, since the first reports on polymeric porous complexes or metal organic frameworks (MOFs) ${ }^{[2]}$ there was an immediate interest in applying the properties of these materials as heterogeneous catalysts. ${ }^{[3-5]}$ However, an initial problem in this area was the poor structural stability of several of these materials that could not with stand the reaction conditions that frequently require the use of solvents, high temperatures or some reagents with basicity, acidity or with ability to act as ligands of metal ions.

The use of MOFs as heterogeneous catalysts requires compositions and structures that can stand the reaction conditions without undergoing irreversible structural damage, allowing their recyclability in consecutive runs. For this reason, even though the number of MOFs already reported is very large, ${ }^{[6-8]}$ the attention has been focussed primarily on only a few of them that have become among the preferred materials for their use in catalysis. One of these favourite MOFs is UiO-66.

\subsection{Structure and properties of UiO-66}

The building unit, linker and the structure of this material are presented in Figure 1 and Table 1. ${ }^{[9]} \mathrm{UiO}-66$ is constituted by $\mathrm{Zr}_{6} \mathrm{O}_{4}(\mathrm{OH})_{4}$ nodes having the six $\mathrm{Zr}^{4+}$ ions in octahedral geometry and the four oxygen atoms or hydroxyl at the centers of each of the facets of the octahedra. These nodes are coordinated with twelve terephthalate (BDC) ligands in such a way that each $\mathrm{Zr}$ atom becomes coordinated with eight oxygen atoms in a square antiprismatic geometry. The structure is defined by two types of cages with tetrahedral $(0.7 \mathrm{~nm})$ and octahedral $(0.9 \mathrm{~nm})$ shapes that can be accessed through triangular windows of about $0.6 \mathrm{~nm}$. The surface area of UiO-66 depends on the preparation method and the presence of defects and it can range from about 800 to $1200 \mathrm{~m}^{2} / \mathrm{g}$. 


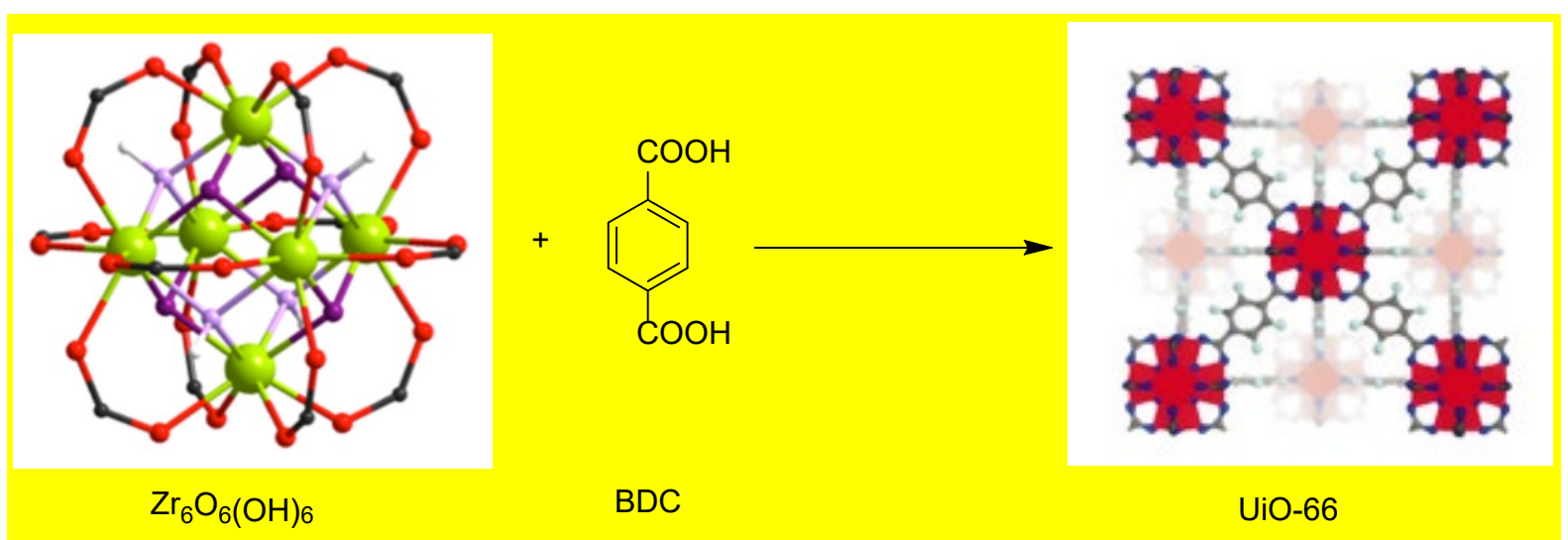

Figure 1. Nodal building unit, linker and structure of UiO-66. Reproduced with permission from ref [9]. Copyright 2008 American Chemical Society.

As commented above, one of the most relevant properties of UiO-66 that explains its wide use in heterogeneous catalysis is its high structural stability. ${ }^{[10]}$ This material can be heated at temperatures about $375{ }^{\circ} \mathrm{C}$, without collapsing the structure although some dehydration and rearrangement of the coordination around the $\mathrm{Zr}^{4+}$ ions can occur. This change in the coordination number of $\mathrm{Zr}^{4+}$ from eight to seven that take place upon dehydration at temperatures above $300{ }^{\circ} \mathrm{C}$ can be reversibly restored to the situation of the as-synthesised material by subsequent hydration.

This remarkable thermal stability is complemented with a high stability in a wide range of organic solvents and water. In aqueous solutions, UiO-66 is stable in a wide range of $\mathrm{pH}$, acid and basic, at moderate temperatures. Also, UiO-66 is stable in the presence of corrosive reagents, such as $\mathrm{HCl}$ and amines, among others. All these stability data made possible the use of UiO-66 as catalysts in a large variety of conditions and reactions that will not be possible for many other MOFs.

Table 1. Building unit, ligand, formula and typical values for surface area, pore volume and pore windows of UiO-66.

\begin{tabular}{|l|l|l|l|l|l|}
\hline Building unit & Ligand & $\begin{array}{l}\text { Molecular } \\
\text { formula }\end{array}$ & $\begin{array}{l}\text { BET } \\
\text { surface }\end{array}$ & $\begin{array}{l}\text { Pore } \\
\text { volume } \\
\left(\mathrm{cm}^{3} / \mathrm{g}\right)\end{array}$ & $\begin{array}{l}\text { Pore } \\
\text { windows } \\
(\mathrm{nm})\end{array}$ \\
\hline
\end{tabular}




\begin{tabular}{|l|l|l|l|l|l|}
\hline & & $\begin{array}{l}\text { area } \\
\left(\mathrm{m}^{2} / \mathrm{g}\right)\end{array}$ & & \\
\hline \\
\hline
\end{tabular}

\subsection{Synthesis of UiO-66}

UiO-66 is easily prepared by solvothermal synthesis in DMF using $\mathrm{ZrCl}_{4}$ and $\mathrm{BDC}$ in the presence of amines at $130{ }^{\circ} \mathrm{C} \cdot{ }^{[9,11]}$ This initial conditions typically leads to particles about 1-2 $\mu \mathrm{m}$ that are not suitable for single crystal characterization. A relevant discovery that has led to UiO-66 samples with higher crystallinity and constituted by particles with defined octahedral shape and larger particle size was achieved by applying the concept of modulators in the synthesis, benzoic acid being one typical example ${ }^{[12]}$ and other parameters like synthesis temperature and/or BDC: $\mathrm{Zr}$ ratio. ${ }^{[13]}$ Modulators are substances that can compete with the coordination of $\mathrm{BDC}$ with $\mathrm{Zr}^{4+}$ ions in a reversible way and, for this reason they are generally also carboxylic acids. ${ }^{[14]}$ The presence of modulators during the synthesis limits the number of crystal seeds and controls the growth of the particles by the occurrence of many binding and debinding events during the crystallization of the materials. In this way, appropriate amounts of modulator produce crystals of larger dimensions by diminishing the number of seeds. In addition, the crystals are also significantly more crystalline and adequate for single crystal XRD structural analysis.

Furthermore, other modulators, acting in a similar way, but, with some stronger binding on the $\mathrm{Zr}^{4+}$ ions in such a way that they can become attached in the final solid, can serve to introduce in a controlled way defects in the UiO-66 structure by remaining coordinated to the metal nodes after the synthesis of the solid..$^{[15-17]}$ One of the examples of these modulators used in the generation of defects in the structure is trifluoroacetic acid under synthesis conditions 
typically employing $\mathrm{HCl}$. This Brönsted acid plays a dual role when $\mathrm{ZrCl}_{4}$ is used as precursor. On one hand, by the common ion effect, $\mathrm{HCl}$ disfavours hydrolysis of this zirconium precursor that becomes slow, while on the other hand, the Brönsted acidity shifts the equilibrium of carboxylic acids decreasing the concentration of carboxylates to bind on the $\mathrm{ZrCl}_{4}$ ions.

The above comment on the synthesis of UiO-66 serves to illustrate the possibility to prepare this MOF in a controlled way ranging from large crystallinity with low density of defects to small crystallites containing some modulator that upon thermal activation would lead to coordinatively unsaturated sites (CUS) on the $\mathrm{Zr}^{4+}$ ions. The presence of CUS is highly relevant from the catalytic point of view since the ideal octahedral coordination of $\mathrm{Zr}^{4+}$ ions does not allow in principle this ion to act as Lewis acid to bind with substrates or reagents. It will be shown in this review that the presence of defects results generally in samples with much higher catalytic activity without the presence of these defects being highly detrimental to the structural stability.

The reader is also referred to the existing literature for detailed synthetic procedures along with their experimental conditions for the synthesis of UiO-66 and related materials, ${ }^{[18,}$ ${ }^{19]}$ including Hf-based MOF analogs. ${ }^{[20]}$ In addition, considering the high thermal and chemical stability of UiO-66, this material can be subjected to a variety of post-synthetic modifications including covalent modifications at the linker, linker and metal exchange, cluster modifications, surface transformations, metalations ${ }^{[21,22]}$ and mixed linker approach ${ }^{[23]}$ among others. Some of these possibilities will be commented in this review as a way to introduce additional functionalities enabling the use of these materials as catalysts.

\section{Scope and concept of the review}

As commented in the previous section, UiO-66 is among the preferred MOFs as heterogeneous catalyst. The reasons for this prevalent use of UiO-66 in catalysis are mainly its high structural stability and robustness combined with large surface area and reliability of 
synthesis and post-synthetic procedures. The last point concerning the synthesis is closely related with more recent strategies to create and control the density of structural defects, allowing in this way the comparison between the performances of highly crystalline materials with those of other UiO-66 samples with increased population of defects.

The present review has been organized according to the type and nature of active sites present in UiO-66 that are responsible for the catalytic activity. The first section describes examples in where UiO-66 has been used as acid or redox catalysts due to the activity located at the nodes. Another section deals with the activity of substituents at BDC as active sites. Particular attention has been paid to $\mathrm{SO}_{3} \mathrm{H}$ as Brönsted acid sites and amino groups in UiO-66$\mathrm{NH}_{2}$ either to promote base-catalyzed reactions or as anchoring site to perform post-synthetic modifications of the initial material attaching covalently in satellite positions metal complexes or other moieties with catalytic activity. The following section deals with the use of UiO-66 and UiO-66- $\mathrm{NH}_{2}$ as host of metal nanoparticles (NPs), metal oxides or other guests those are responsible for the catalytic activity of the material. When possible, emphasis has been made in showing the advantages of selecting UiO-based catalysts compared to other MOFs or other types of catalysts, trying to present evidence confirming recyclability and structural stability under reaction conditions. A summary of the current achievements and our views on future developments are provided in final section.

\section{Metal nodes as active sites}

\subsection{Nodes as Lewis acids}

The catalytic activity of UiO-66 as Lewis acid can be drastically increased by the introduction of defects ${ }^{[24]}$. One general strategy to create structural defects is to perform the UiO-66 synthesis in the presence of appropriate concentrations of a carboxylic acid different from the BDC linker. This second carboxylic acid is generally termed as modulator. By using a modulator such as, for instance, trifluoroacetic acid in different concentrations in the range 
of 0-20 equiv with respect to BDC, the resulting defective UiO-66 exhibits enhanced Lewis acidity.

This defective UiO-66 obtained in the presence of trifluoroacetic acid was tested on the "ene"-type cyclization of citronellal to isopulegol (Scheme 1). ${ }^{[25]}$ A regular UiO-66 sample obtained in the absence of modulator reached a conversion of $34 \%$, while UiO-66-20 (20 refers to the percentage of trifluoroacetic acid) was able to convert $75 \%$ of citronellal at the same time. It was observed that the catalytic activity of the samples was gradually increased by increasing modulator proportion from 0 to 20 (Figure 2). This influence of the percentage of trifluoroacetic acid on the catalytic activity is in agreement with the assumption that the increase in activity is due to the creation of a larger number of open sites on the $\mathrm{Zr}_{6}$ clusters, rather than to a modified acid strength. On the other hand, the use of even larger quantities of modulator during the synthesis did not increase further the activity of materials, indicating that there is a maximum in the catalytic activity that can be achieved by the introduction of defects.<smiles>C=C(C)C1CCC(C)CC1O[Mg]OC(C)(C)C</smiles>

Scheme 1. Conversion of citronellal to isopulegol.

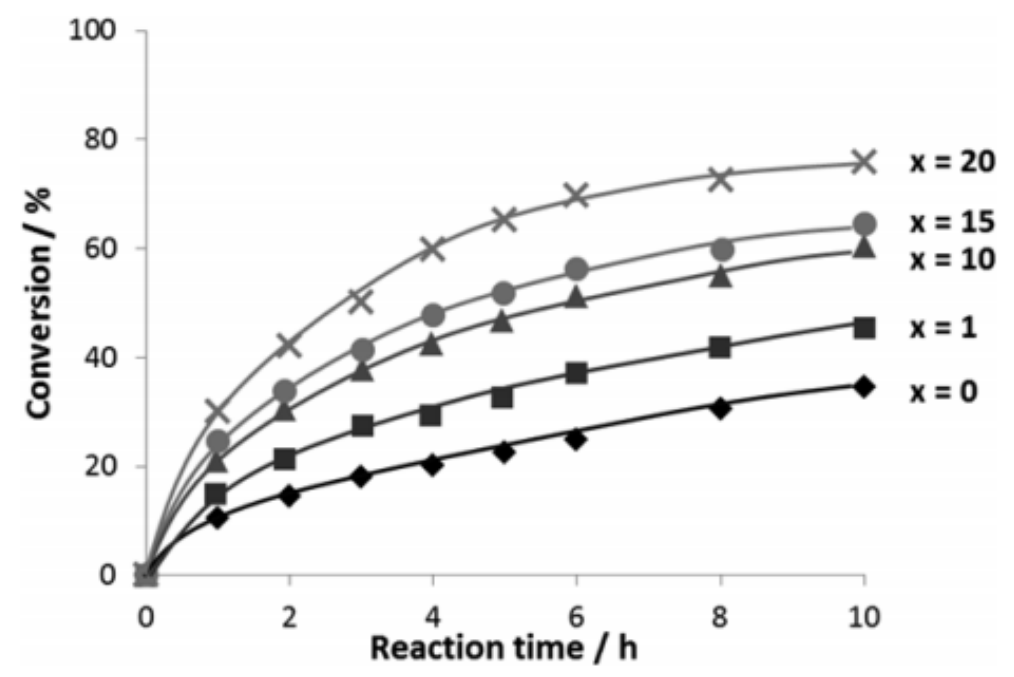


Figure 2. Conversion of citronellal over UiO-66-X vs time, $\mathrm{X}$ meaning the proportion of trifluoroacetic acid used in the synthesis respect to BDC. Reproduced with permission from ref [25]. Copyright 2013 American Chemical Society.

UiO-66 with or without thermal activation has been reported as heterogeneous catalyst in the cyanosilylation of benzaldehyde. ${ }^{[26]}$ It was observed that both activated and unactivated samples exhibited $96 \%$ conversion of benzaldehyde at $40{ }^{\circ} \mathrm{C}$. Furthermore, when acetic acid was present in the synthesis of the material, the conversion of benzaldehyde dramatically enhanced to $98 \%$ in shorter time under identical conditions. These results clearly indicate that the presence of acetic acid during UiO-66 synthesis enhances the catalytic performance of UiO66. It is worth noting that acetic acid in the absence of UiO-66 shows only $10 \%$ of benzaldehyde conversion. Very recently, a beneficial influence of water in the Fischer esterification was reported using UiO-66 as solid catalyst. ${ }^{[27]}$ These catalytic data seem to be in accordance with the well-established enhancement of the catalytic activity of UiO-66 by tuning the nature of defective sites in the solid material. ${ }^{[28,29]}$

UiO-66 and UiO-67 were tested as heterogeneous solid catalysts for the acetalization of benzaldehyde with methanol. Working at room temperature under identical conditions, UiO66 exhibited better conversion $\left(91 \%\right.$ ) of benzaldehyde, while UiO-67 gave $86 \% \cdot{ }^{[30]}$ Based on theoretical calculations and modelling, it was proposed that accessibility of substrates to internal active sites can play a dominant role over the Lewis acidity of Zr-MOF for large substrates. UiO-66 was reused four runs with no decay in the conversion of benzaldehyde.

Besides acetalization, esterification of carboxylic acid is other general reaction type requiring acid catalysis. It has been reported that UiO-66 and UiO-66- $\mathrm{NH}_{2}$ are active and stable catalysts for the acid catalyzed esterification of various saturated and unsaturated fatty acids with methanol and ethanol. ${ }^{[31]}$ For instance, UiO-66 and UiO-66- $\mathrm{NH}_{2}$ exhibited 94 and $99 \%$ yield of methyl laurate at $60{ }^{\circ} \mathrm{C}$ with a TOF value of 16 and $25 \mathrm{~h}^{-1}$. In spite of UiO-66- $\mathrm{NH}_{2}$ 
having less and weaker acid sites compared to UiO-66, the higher catalytic activity of the former can be explained by the occurrence of a dual acid/base activation mechanism. In this dual activation, both substrates lauric acid at the acid sites and methanol at the $-\mathrm{NH}_{2}$ substituents, in close proximity become promoted towards ester formation. In contrast, UiO66 lacking these amino groups, cannot benefit from a dual acid/base activation mechanism and must rely only on the Lewis acid sites to catalyze the reaction. This concept of dual acid/base activation is very interesting as a way to increase the catalytic activity and, certainly deserves further attention to be completely understood.

Recently, an attempt was made to prepare UiO-66 powders in a $100 \mathrm{~L}$ pilot scale batch reactor using industrial grade solvent and commercially available BDC as ligand. Large scale synthesis are always prone to produce less crystalline samples, with larger density of defects than those obtained in small batches under optimal synthetic conditions. But, in the present case, this lower crystallinity could be positive from the point of view of its catalytic activity. These UiO-66 samples prepared in larger batch were applied as catalysts for $\mathrm{CO}_{2}$ cycloaddition of styrene oxide (Scheme 2). ${ }^{[32]}$ UiO-66 powder showed $94 \%$ conversion with $100 \%$ selectivity at $100{ }^{\circ} \mathrm{C}$. In contrast, the use of ground/sieved UiO-66 pellet showed $92 \%$ conversion after longer reaction time. The reaction was heterogeneous in nature and the catalytic activity of these materials was retained in three consecutive cycles. Furthermore, powder XRD of the fresh and three times reused catalysts showed identical pattern, thus, indicating the stability of these UiO-66 samples prepared in large scale batch. In another precedent, the same group has reported both UiO-66 and UiO-66- $\mathrm{NH}_{2}$ as solid heterogeneous catalyst for the cycloaddition of $\mathrm{CO}_{2}$ to styrene oxide exhibiting after $1 \mathrm{~h}$, at $60{ }^{\circ} \mathrm{C}, 70$ and 48 $\%$ conversions for the former and latter catalyst respectively. ${ }^{[33]}$ However, both catalysts afforded around $94 \%$ conversion after $4 \mathrm{~h}$ under identical conditions. 


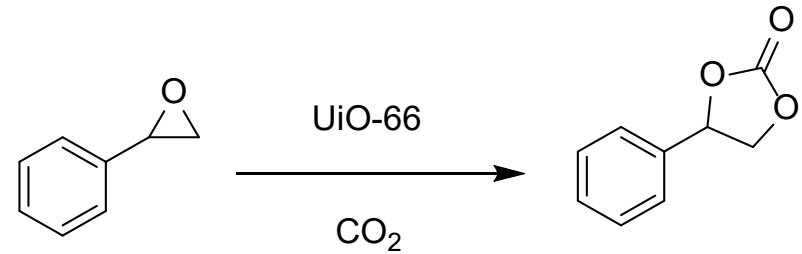

Scheme 2. Cycloaddition of $\mathrm{CO}_{2}$ to styrene oxide catalyzed by UiO-66.

Recently, UiO-66 has been reported as solid acid catalyst for the synthesis of a series of heterocycles under mild reaction conditions. These reactions generally imply condensation of two or more components, cyclization and aromatization, the last step being the driving force for these reactions. As an example, UiO-66 is a robust catalyst for the synthesis of various nitrogen-containing heterocycles, including imidazopyridines and pyridine derivatives. ${ }^{[34]}$ Under the optimized reaction conditions, UiO-66 afforded at room temperature under solventfree conditions $93 \%$ yield of 3-(N-cyclohexyl)amine-2-phenylimidazo[1,2-a]pyridine (Scheme 3). Similarly, UiO-66 at $100{ }^{\circ} \mathrm{C}$ under solvent-free conditions exhibited $91 \%$ yield of 2,4,6-triphenylpyridine (Scheme 3). The catalyst was recycled for three cycles. The powder XRD and FT-IR data indicated no structural changes in the recycled catalyst compared to the fresh one.

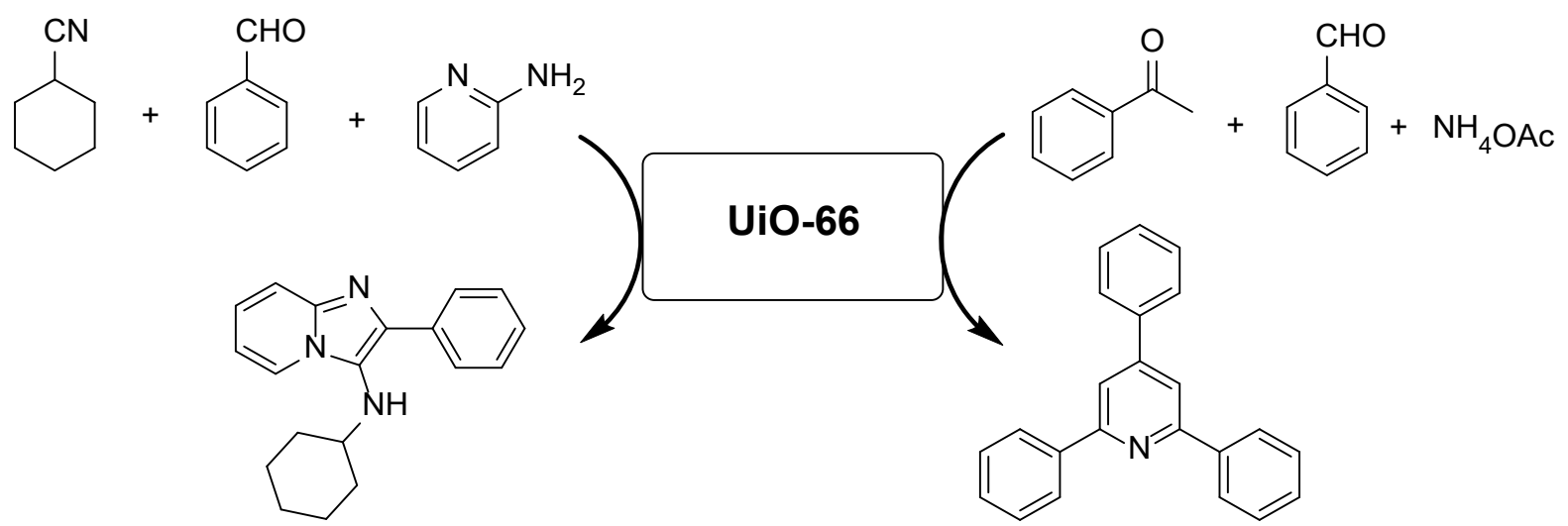

Scheme 3. UiO-66 mediated synthesis of nitrogen heterocycles.

In another report, UiO-66 and UiO-66- $\mathrm{NH}_{2}$ were found to be efficient diastereoselective catalysts for the one-pot synthesis of a pyrano[3,2-c]quinoline through an inverse electron-demand aza-Diels-Alder [4+2] cycloaddition of an aryl imine (formed in situ 
by condensation of aniline and benzaldehyde) and 3,4-dihydro-2H-pyran (Scheme 4). ${ }^{[35]} \mathrm{UiO}-$ 66 and $\mathrm{UiO}-66-\mathrm{NH}_{2}$ afforded 83 and $88 \%$ yield of pyrano[3,2-c] quinoline, with 94 and $88 \%$ of diastereomeric excesses for the trans isomer, respectively, at room temperature. Under identical conditions, MIL-101(Cr), MIL-101(Al)-NH2 and MIL-101(Fe)-NH2 showed lower than $5 \%$ yield of the product, suggesting the superior activity of UiO-66, in spite that the structure of MIL-101 materials has open coordination sites on the metal ion that should be absent in ideal UiO-66. It is likely that defects on the structure of UiO-66 are the factor responsible for its remarkable catalytic activity over the MIL-101 analogues. These solids were reused at least three times without significant loss in activity or diastereoselectivity.<smiles>Nc1ccccc1C=O</smiles>

Scheme 4. Stereoselective synthesis of pyrano[3,2-c]quinolines mediated by UiO-66.

\subsection{Nodes as redox sites}

Recently, cerium has been incorporated onto the structure of UiO-66 and XANES characterisation showed its presence in the hexameric nodal building units, in the form of two oxidation states, predominantly as $\mathrm{Ce}(\mathrm{IV})$, but also in lesser proportion as $\mathrm{Ce}(\mathrm{III}) .{ }^{[36]}$ The mixed-metal UiO-66 material exhibited enhanced binding of methanol as evidenced by FT-IR spectroscopy. This stronger adsorption of methanol due to the presence of Ce favours the catalytic oxidation of methanol into $\mathrm{CO}_{2}$.

Different UiO-66 catalysts were prepared with or without crystallization agent $(\mathrm{HCl})$ and/or a modulator (trifluoroacetic acid) to alter purposely the final structural and chemical properties of the materials and the activity of this series of defective UiO-66 was studied in the oxidative desulfurization reaction. ${ }^{[37]}$ Better desulfurization performance was observed in the oxidation of dibenzothiophene using hydrogen peroxide in acetonitrile for UiO-66 
(nonmodulated procedure and without the use of $\mathrm{HCl}$ ). In contrast, poor activity was observed for the more crystalline samples, namely, $\mathrm{UiO}-66_{\mathrm{HCl}}$ and $\mathrm{UiO}-66_{\mathrm{HCl}, \mathrm{mod}}$ for the same reaction under identical conditions. UiO-66 was reused for three consecutive cycles. Furthermore, UiO66 showed highly efficient desulfurization of a real diesel fuel (81\%).

A series of Zr-MOFs with different ligand functionalities and porosities like UiO-66, UiO-66- $\mathrm{NH}_{2}$ and $\mathrm{UiO}-66-\mathrm{COOH}$ were examined in the conversion of ethyl levulinate to $\gamma$ valerolactone (GVL) using isopropanol through catalytic transfer hydrogenation $(\mathrm{CTH})$ reaction (Scheme 5). ${ }^{[38]}$ The maximum yield of GVL (up to $92.7 \%$ ) was achieved using UiO$66(\mathrm{Zr})$ as catalyst at $200{ }^{\circ} \mathrm{C}$. On the other hand, zirconium trimesate, MOF-808 exhibited the highest GVL formation rate $\left(94.4 \mu \mathrm{mol} \mathrm{g}{ }^{-1} \mathrm{~min}^{-1}\right)$ among the catalysts tested at $130{ }^{\circ} \mathrm{C}$. UiO66 and MOF-808 were recycled at least five times without a notable change in catalytic activity and product selectivity. Powder XRD of the reused samples indicated a decrease in the peak intensity compared to the fresh samples, but, however, the activity was maintained. In another report, UiO-66 was also found to promote the Meerwein-Ponndorf-Verley reduction using isopropanol as reducing agent to achieve complete conversion of cinnamaldehyde with $94 \%$ selectivity to cinnamyl alcohol at $120^{\circ} \mathrm{C} .^{[39]}$

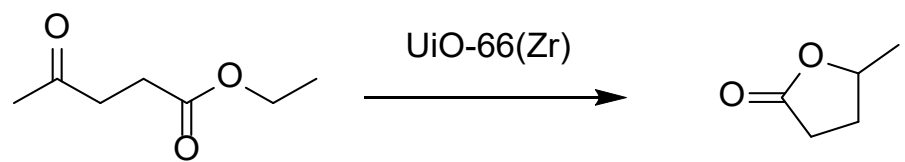

Scheme 5. Conversion of ethyl levulinate to GVL catalyzed by UiO-66(Zr).

UiO-66 and NU-1000 have also been used as porous hosts to anchor some Ir complexes. In some of these examples, chemisorption of $\operatorname{Ir}(\mathrm{CO})_{2}$ and $\operatorname{Ir}\left(\mathrm{C}_{2} \mathrm{H}_{4}\right)_{2}$ complexes takes place by anchoring $\mathrm{Ir}$ at the $\mathrm{OH}$ groups of $\mathrm{Zr}_{6}(\mathrm{OH})_{4} \mathrm{O}_{4}$. The activity of $\mathrm{Nu}-1000$ and UiO-66 containing $\operatorname{Ir}\left(\mathrm{C}_{2} \mathrm{H}_{4}\right)_{2}$ complex for ethylene hydrogenation were 0.010 and $0.017 \mathrm{~s}^{-1}$, respectively at 25 ${ }^{\circ} \mathrm{C} \cdot{ }^{[40]}$ 
Analogously, the $\mathrm{OH}$ groups present on UiO-66 at the nodal octahedral planes have been metallated with $\mathrm{V}^{\mathrm{V}}$ ions to give a vanadium containing sample, $\mathrm{V}-\mathrm{UiO}-66$. The activity of V-UiO-66 was checked in the vapour-phase oxidative dehydrogenation of cyclohexene, ${ }^{[41]}$ observing $100 \%$ selectivity to benzene at $2 \%$ conversion. Selectivity to benzene remained up to $80 \%$ of cyclohexene conversion, showing that $\mathrm{V}-\mathrm{UiO}-66$ is a robust catalyst that can operate in a broad range of reaction conditions. In addition, as evidenced by powder XRD, ICP-AES analysis and SEM images, $\mathrm{V}-\mathrm{UiO}-66$ maintains the structural integrity in a large extent at temperatures as high as $350{ }^{\circ} \mathrm{C}$. This behaviour is in accordance with the reported thermal stability of UiO-66 determined by thermogravimetry as commented earlier.

Other examples in the literature reporting the use of UiO-66 type materials as catalysts for the oxidation of benzyl alcohol, ${ }^{[42]}$ thiophenol, ${ }^{[43]}$ cyclohexene ${ }^{[44]}$ and $\mathrm{Ti}^{\mathrm{iV}}$ supported as part of the node in UiO-66 for the oxidation of cyclohexene using hydrogen peroxide ${ }^{[45]}$ have also been reported.

\section{Functionalized BDC in UiO-66}

\section{$4.1 \mathrm{UiO}-66-\mathrm{SO}_{3} \mathrm{H}$ as solid acid}

Due to sustainability, biomass transformation into chemicals is gaining importance in the chemical industry to provide bulk and commodity chemicals. ${ }^{[46,47]}$ Cellulose and related polysaccharides are the major components of biomass and their transformation involve several steps, ${ }^{[46]}$ including depolymerisation to glucose, glucose isomerization to fructose and fructose dehydration to hydroxymethylfurfural (HMF) (Scheme 6). All these steps require Brönsted acids, and typically homogeneous soluble acids such as $\mathrm{HCl}$ are employed in some of these steps. It would be more convenient if these liquid acids could be replaced by solid acids, one of the possibilities being to introduce sulfonic acid groups on the linker of MOFs to obtain a solid sulfonic acid. 


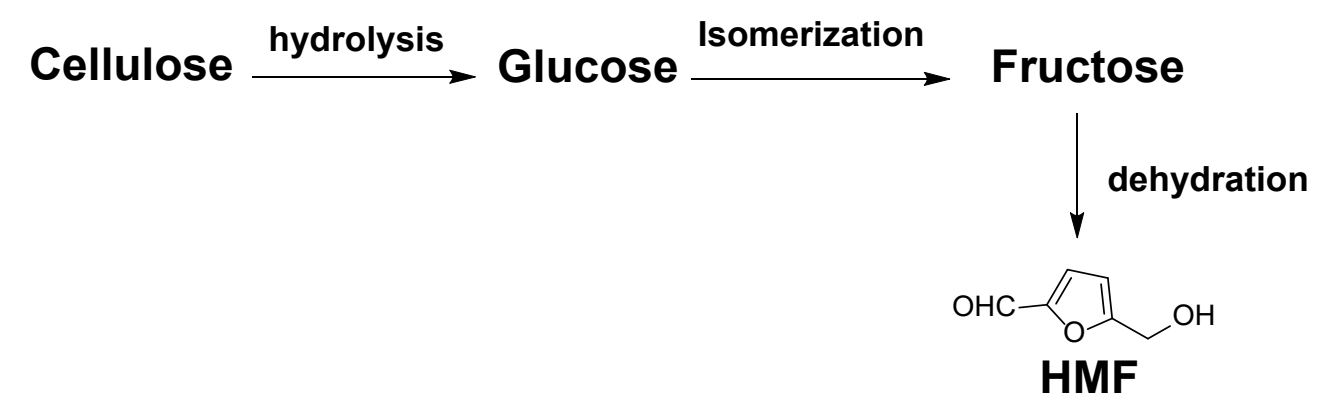

Scheme 6. Series of reactions involved in the transformation of cellulose to HMF.

The synergy between $\mathrm{Zr}_{6}(\mathrm{OH})_{4} \mathrm{O}_{4}$ nodes and sulfonic groups at the BDC linkers has been claimed to occur in UiO-66, leading to an enhanced catalytic activity for this material compared to other MOFs. Post-synthetic modification is a viable strategy to introduce sulfonic groups. ${ }^{[22]}$ Very recently, UiO-66- $\mathrm{SO}_{3} \mathrm{H}$ was prepared by partial replacement of $\mathrm{BDC}$ in UiO66 with 2-monosulfo-benzene-1,4-dicarboxylate (MSBDC) and its activity in the conversion of glucose to fructose and HMF in water was studied. ${ }^{[48]}$ Again, it has been proposed that UiO66- $\mathrm{SO}_{3} \mathrm{H}$ behaves as a bifunctional solid interacting Lewis and Brönsted acid sites. This type of interaction between Lewis acid and Brönsted sites has been previously claimed in other solid acids, like zeolites. ${ }^{[49,50]}$ UiO-66-SO $3 \mathrm{H}-20$ exhibited $31 \%$ glucose conversion with combined product selectivity of HMF and fructose to $90 \%$ at $140{ }^{\circ} \mathrm{C}$ in water (Figure 3). This activity was comparable to the activity reported by Sn-beta zeolite, a benchmark solid catalyst for glucose-fructose isomerization in water. ${ }^{[51]} \mathrm{UiO}-66-\mathrm{SO}_{3} \mathrm{H}-20$ was recyclable for three times, although the activity dropped after the first cycle. However, the crystalline structure characteristic of UiO-66 was preserved after three cycles. 


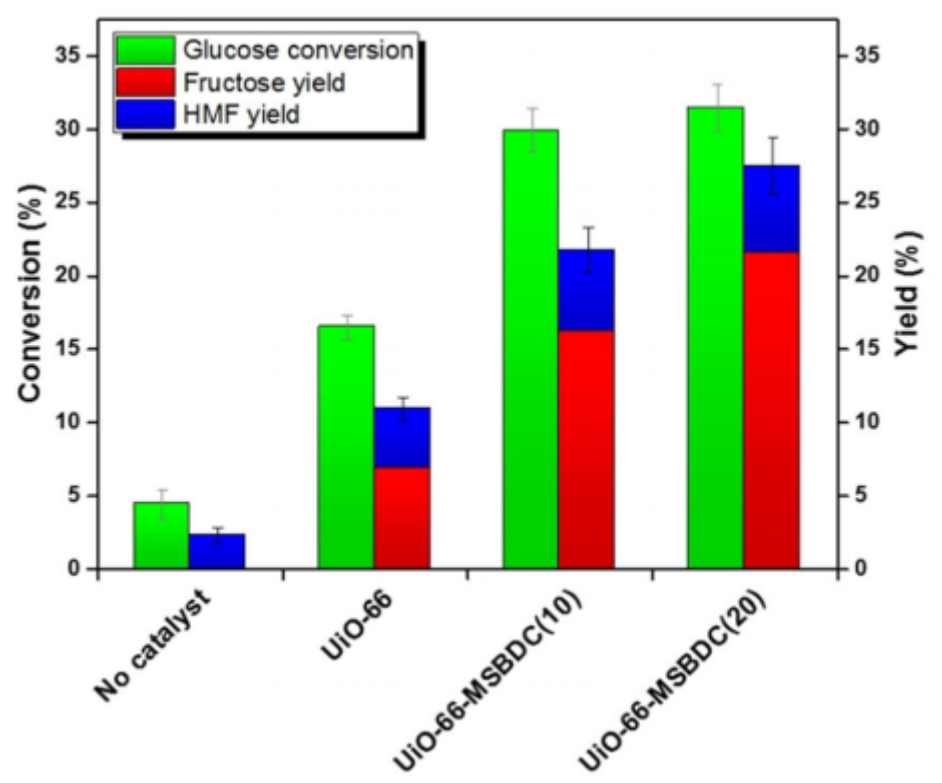

Figure 3. Isomerization of glucose in water using UiO-66, UiO-66-MSBDC(10) and UiO-66MSBDC(20) as catalysts. Reproduced with permission from ref [48]. Copyright 2018 Wiley. In another precedent, other $\mathrm{UiO}-66-\mathrm{SO}_{3} \mathrm{H}(\mathrm{S}$ content $0.32 \mathrm{mmol} / \mathrm{g})$ prepared by postsynthetic modification of the BDC linkers using chlorosulfonic acid was used as heterogeneous catalyst for the transformation of fructose at $99 \%$ conversion to HMF with $85 \%$ yield at 120 ${ }^{\circ} \mathrm{C}$ in DMSO as solvent. ${ }^{[52]}$ In comparison, a slightly higher yield of $90 \%$ was achieved with MIL-101(Cr)-SO ${ }_{3} \mathrm{H}(0.54 \mathrm{mmol} / \mathrm{g})$ for this reaction under identical conditions. However, this difference in the activity in favour to MIL-101(Cr)-SO ${ }_{3} \mathrm{H}$ was due to the different acid density and $\mathrm{S}$ content in these two MOFs, implying that the two MOF types can exhibit similar catalytic activity when the values of activity are corrected taking into account the number of sulfonic acid groups.

The use of high-cost noble metal catalysts and operational problems associated with high-pressure hydrogen required in the reaction poses a serious limitation in the large-scale production of GVL from methyl levulinate, one of the key routes to transform cellulose into valuable platform industrial chemicals. ${ }^{[53]}$ One of the ways to overcome these issues associated to the harsh reaction conditions needed for hydrogenation of carbonylic groups is the development of new catalysts for the CTH reaction using alcohols as hydrogen donors for this 
reaction. ${ }^{[54,55]}$ In this context, $\mathrm{UiO}-66-\mathrm{SO}_{3} \mathrm{H}\left(60 \mathrm{~mol} \%\right.$ of $\mathrm{SO}_{3} \mathrm{H}$ functionalized linker by postsynthetic sulfonation of parent UiO-66) exhibited the highest catalytic activity in the $\mathrm{CTH}$ reaction of methyl levulinate and 2-butanol to give GVL with $85 \%$ yield at $140{ }^{\circ} \mathrm{C}$ (Scheme 7). ${ }^{[56]}$ Control experiments revealed that the high catalytic activity of this $\mathrm{UiO}-66-\mathrm{SO}_{3} \mathrm{H}$ was the cooperative effect between "arrested" Lewis-basic $\mathrm{Zr}_{6} \mathrm{O}_{4}(\mathrm{OH})_{4}$ clusters and Brönstedacidic $-\mathrm{SO}_{3} \mathrm{H}$ sites arranged in a confined nanospace and adjacent each other at close distance, but without undergoing neutralization. UiO-66- $\mathrm{SO}_{3} \mathrm{H}$ was reusable for four times without any decay. Available catalytic data supports the heterogeneity of the process.

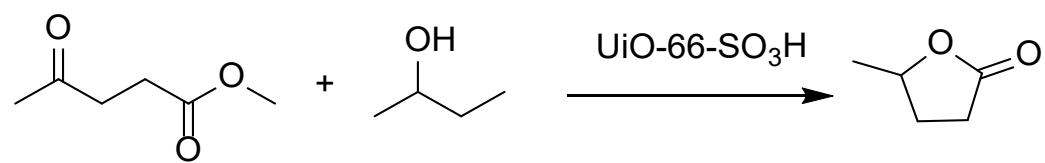

Scheme 7. Conversion of methyl levulinate to GVL catalyzed by $\mathrm{UiO}-66-\mathrm{SO}_{3} \mathrm{H}$ proposed to act as bifunctional acid-basic catalyst.

One of the examples illustrating other ways for post-synthetic modification besides ligand exchange was the preparation of $\mathrm{UiO}-66-\mathrm{RArSO}_{3} \mathrm{H}$ Brönsted acid catalyst by formation of peptide bonds starting from UiO-66- $\mathrm{NH}_{2}$ as shown in Figure 4. The activity of UiO-66$\mathrm{RArSO}_{3} \mathrm{H}$ was tested in the acetalization of benzaldehyde and Morita-Baylis-Hillman (MBH) reactions (Scheme 8). ${ }^{[57]}$ The use of $\mathrm{UiO}-66-\mathrm{RArSO}_{3} \mathrm{H}$ as catalyst in acetalization of benzaldehyde with ethanol afforded in $98 \%$ to the corresponding diethyl acetal with a TON and TOF values of 980 and $490 \mathrm{~h}^{-1}$, respectively, at $23{ }^{\circ} \mathrm{C}$. On the other hand, the reaction between benzaldehyde and cyclopentenone using this catalyst and DABCO as promoter exhibited $92 \%$ yield at $23{ }^{\circ} \mathrm{C}$. In addition, a series of acetals and $\mathrm{MBH}$ adducts were prepared using this catalyst. The UiO-66- $\mathrm{ArSO}_{3} \mathrm{H}$ was reused five times for both acetalization and $\mathrm{MBH}$ reactions. In another related report, a similar type of UiO-66 based catalyst using amino groups on $\mathrm{BDC}$ to anchor sulfonic acid groups, namely UiO-66-NH-RSO${ }_{3} \mathrm{H}$ was synthesised and its activity in the acetalization of benzaldehyde with ethanol also evaluated. ${ }^{[58]}$ This catalyst 
afforded $98 \%$ yield of the diethyl acetal at room temperature with a TON value of 71 . The catalytic activity was maintained for six cycles without any decay in the yield.
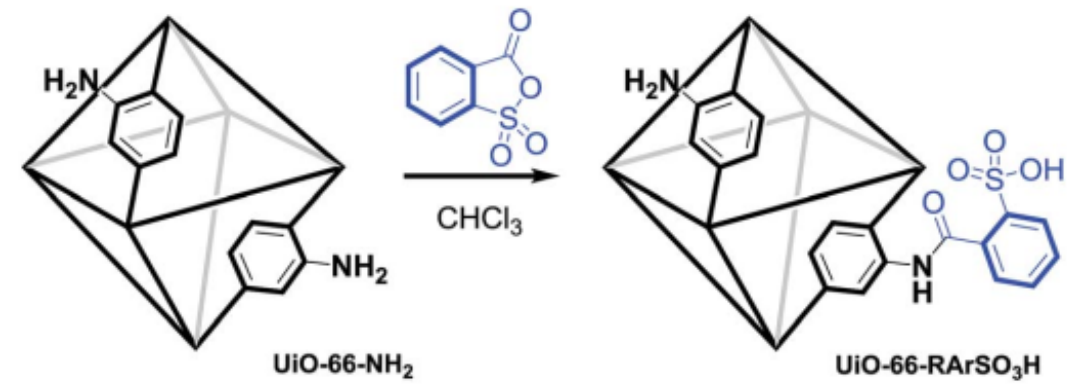

Figure 4. Synthesis of UiO-66-RArSO ${ }_{3} \mathrm{H}$ by post-synthetic modification of UiO-66- $\mathrm{NH}_{2}$. Reproduced with permission from ref [57]. Copyright 2016 Royal Society of Chemistry.<smiles>CCOC(OCC)c1ccccc1</smiles><smiles></smiles>

Scheme 8. UiO-66 $\mathrm{RArSO}_{3} \mathrm{H}$ promoted acetalization of benzaldehyde and Morita-BaylisHillman (MBH) reactions.

Recently, UiO-66- $\mathrm{SO}_{3} \mathrm{H}$ was also reported to promote a multicomponent domino reaction leading to the synthesis of dihydro-2-oxopyrroles. ${ }^{[59]} \mathrm{N}$-aryldihydro-2-oxopyrroles were obtained under optimal reaction conditions in $85 \%$ yield (Scheme 9). Under identical conditions, UiO-66 and $\mathrm{ZrCl}_{4}$ afforded much lower yields of $26 \%$ and $32 \%$ respectively. This enhanced activity of $\mathrm{UiO}-66-\mathrm{SO}_{3} \mathrm{H}$ is proposed to be due to the synergism between Brönsted and Lewis acid sites present at the sulfonic acid groups and $\mathrm{Zr}_{6}(\mathrm{OH})_{4} \mathrm{O}_{4}$ nodes, respectively, a claim that appears to be recurrent for this UiO-66- $\mathrm{SO}_{3} \mathrm{H}$ material. The catalyst maintained its activity for three cycles. 


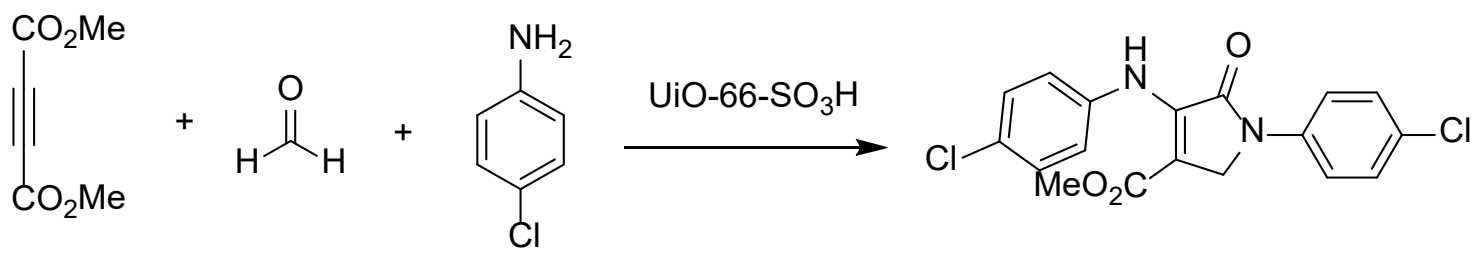

Scheme 9. Multicomponent reaction catalyzed by $\mathrm{UiO}-66-\mathrm{SO}_{3} \mathrm{H}$ as solid catalyst.

Other examples of the catalytic activity of $\mathrm{UiO}-66-\mathrm{SO}_{3} \mathrm{H}$ include Friedel-Crafts alkylation of $p$-xylene. ${ }^{[60]}$

\section{2 $\mathrm{UiO}-66-\mathrm{NH}_{2}$ in catalysis}

Recently, UiO-66 and UiO-66- $\mathrm{NH}_{2}$ were tested as heterogeneous catalysts for the esterification of levulinic acid with ethanol, 1-butanol, lauryl alcohol, cetyl alcohol and oleyl alcohol. ${ }^{[61]}$ These two MOFs were active and selective catalysts for the conversion of levulinic acid to ethyl levulinate (Scheme 10) in quantitative yield at $78^{\circ} \mathrm{C}$. Under identical conditions, blank experiments in the absence of MOF catalysts gave only $5.4 \%$ yield of the ester. UiO-66 and UiO-66- $\mathrm{NH}_{2}$ catalysts were reused three times without significant decay in their activity. Interestingly, it was proved that the catalytic activity of these MOFs was critically dependent on the concentration of defects and particle size. For instance, the TOF values achieved for this esterification using well crystallized UiO-66- $\mathrm{NH}_{2}$ and defective UiO-66- $\mathrm{NH}_{2}$ samples were 29 and $230 \mathrm{~h}^{-1}$, respectively. On the other hand, the esterification of levulinic acid with 1-butanol using $\mathrm{UiO}-66$ and $\mathrm{UiO}-66-\mathrm{NH}_{2}$ as catalysts was 95 and $91 \%$ yields, respectively, which is much superior than the yield observed with H-Beta (82\%), H-Mor $(30 \%)$ and H-Y (32\%) zeolites as catalysts, even at double reaction time. ${ }^{[62]}$ On the other hand, esterification of levulinic acid with longer fatty alcohols with 1-hexadecanol ( $\sim 80 \%$ yield) and oleyl alcohol ( $\sim 60 \%$ yield) showed a considerable drop in the activity compared to 1-dodecanol $(\sim 90 \%$ yield) using UiO-66 as catalyst under identical conditions. It was believed that the activity drop is due to higher adsorption of the fatty acid (or fatty ester product) on the surface of the solid, which caused the progressive (reversible) deactivation of the catalyst. 
<smiles>CCOC(=O)CCC(=O)N[13C](=O)O[Na]</smiles>

Scheme 10. Esterification of levulinic acid by UiO-66 and UiO-66- $\mathrm{NH}_{2}$ as catalysts.

Condensation reactions are considered as general types of $\mathrm{C}-\mathrm{C}$ bond forming reactions that can be promoted by bases, organic amines being possible organocatalysts frequently used. ${ }^{[63]}$ Although generally tertiary amines are preferred, primary and secondary amines can also promote these reactions. In one of the seminal contributions, the cross aldol reaction between benzaldehyde and heptanal was performed at $120{ }^{\circ} \mathrm{C}$ using $\mathrm{UiO}-66-\mathrm{NH}_{2}$ as catalyst reaching a conversion of $67 \%$ with $91 \%$ selectivity to jasminaldehyde (Scheme 11). In contrast, the parent UiO-66 gave $42 \%$ benzaldehyde conversion with $81 \%$ selectivity to jasminaldehyde under identical conditions. ${ }^{[64]}$ This difference in activity was attributed due to the close proximity of Lewis acid sites and basic amino groups inside the cages in UiO-66- $\mathrm{NH}_{2}$ disfavouring in this way the byproduct derived of heptanal homo coupling and increasing the cross aldol product.

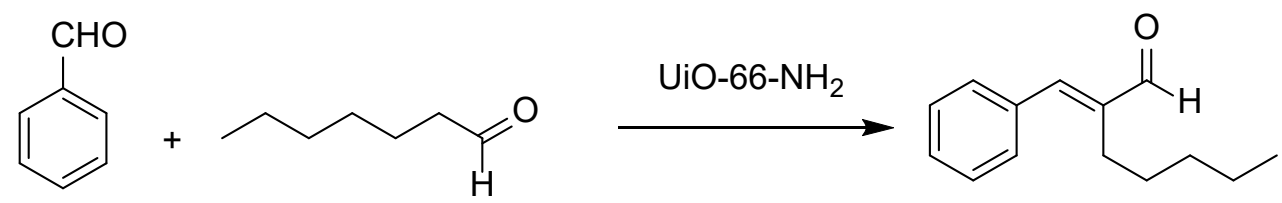

Scheme 11. UiO-66- $\mathrm{NH}_{2}$ promoted synthesis of jasminaldehyde.

In another precedent, UiO-66- $\mathrm{NH}_{2}$ was reported as a heterogeneous catalyst for Knoevenagel condensation of benzaldehyde with ethyl cyanoacetate or malononitrile. ${ }^{[65]} \mathrm{UiO}-$ $66-\mathrm{NH}_{2}$ afforded $94 \%$ conversion for the reaction of benzaldehyde with ethyl cyanoacetate in ethanol at $80{ }^{\circ} \mathrm{C}$. On the other hand, the reaction between benzaldehyde and malononitrile using UiO-66- $\mathrm{NH}_{2}$ afforded $98 \%$ conversion at $40{ }^{\circ} \mathrm{C}$ in much shorter time. This relative reactivity of ethyl cyanoacetate and malononitrile follows the higher $\mathrm{C}-\mathrm{H}$ bond acidity and 
lower molecular dimensions of the latter active methylene compound. The catalytic performance of UiO-66- $\mathrm{NH}_{2}$ was also screened for various aromatic aldehydes with malononitrile, reaching in all cases conversions higher than $90 \%$ under mild conditions. The catalyst was recycled for three cycles without losing its framework integrity and without decrease in the catalytic activity for the reaction of benzaldehyde with malononitrile. As commented previously in the case of sulfonic groups attached to BDC, also in this case, the superior activity of $\mathrm{UiO}-66-\mathrm{NH}_{2}$ with respect to other catalysts was attributed to the siteisolated bifunctional acid-base character of the catalyst due to the presence of $\mathrm{Zr}$ sites which are in close proximity to the amino groups, thus, activating aldehydes to promote the formation of aldimine intermediates from the aldehyde and the amino group.

The activity for the aldol condensation can be increased by introducing basic amino groups through proper ligand functionalization, thus, creating a bifunctional acid-base catalyst. $^{[64]}$ In this aspect, DFT calculations have shed light on the mechanism of the cross- and self-aldol condensations of benzaldehyde and propanal. ${ }^{[66]}$ It was concluded that the mechanism on UiO-66 and UiO-66- $\mathrm{NH}_{2}$, is essentially the same, although the amino functionalized MOF exhibits a slightly stronger reactant adsorption and slightly lower activation barriers, thus, explaining its higher initial activity. Furthermore, although the initial activity towards cross-aldol condensation on the amino functionalized material was higher, over the course of reaction the activity of $\mathrm{UiO}-66-\mathrm{NH}_{2}$ and $\mathrm{UiO}-66$ levels off.

In another work, a post-synthetic modification strategy was employed for the rapid and facile attachment of a primary alkyl amino group at the $\mathrm{NH}_{2}$-BDC linker to obtain a series of MOFs (Figure 5) and the resulting UiO-66-NH- $\mathrm{RNH}_{2}, \mathrm{MIL}-101(\mathrm{Cr})-\mathrm{NH}-\mathrm{RNH}_{2}$ and MIL53(Al)-NH- $\mathrm{RNH}_{2}$ samples were evaluated as catalysts in the Knoevenagel condensation between benzaldehyde and malononitrile. ${ }^{[67]}$ It was observed that UiO-66-NH-RNH 2 and MIL101(Cr)-NH-RNH 2 catalysts afforded 97 and $99 \%$ yields, respectively, towards the expected 
condensation product at room temperature. On the other hand, MIL-53(Al)-NH-NH gave $^{-} 7$ $\%$ yield for this reaction under identical conditions. The UiO-66-NH-RNH $\mathrm{H}_{2}$ and MIL-101(Cr)$\mathrm{NH}-\mathrm{RNH}_{2}$ catalysts were used for five runs with no loss in their activity.<smiles>Nc1cc(C(CO)CO)ccc1C(CO)CO</smiles>

\section{Amino-tagged} MOF

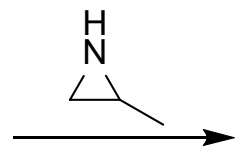

0

MOF-RNH 2

Figure 5. Synthesis of UiO-66-NH- $\mathrm{RNH}_{2}$.

Recently, computational DFT calculations on eight different Lewis acid/base pair moieties in functionalized UiO-66 as catalysts have been performed to understand their activity for $\mathrm{CO}_{2}$ hydrogenation to give formic acid. ${ }^{[68]}$ It was concluded that the reaction of $\mathrm{CO}_{2}$ with $\mathrm{H}_{2}$ catalyzed by UiO-66-X materials always proceeds by a two-step mechanism, with the first step being heterolytic dissociation of $\mathrm{H}_{2}$ on the Lewis acid/base pair. The second step consists in the concerted addition to $\mathrm{CO}_{2}$ of a hydride and a proton to give formic acid. The $\mathrm{H}_{2}$ dissociation barriers range from 0.48 to $1.09 \mathrm{eV}$ and the barriers for $\mathrm{CO}_{2}$ hydrogenation between 0.28 and $1.79 \mathrm{eV}$.

There are other reports in the literature using $\mathrm{UiO}-66-\mathrm{NH}_{2}$ as heterogeneous solid catalyst for acetalization of benzaldehyde, ${ }^{[69]}$ conversion of N-hydroxycarbamates into Nhydroxy-oxazolidinones ${ }^{[70]}$ or as a starting material for the construction of metal complexes exhibiting catalytic activity in the Suzuki and Heck cross-couplings, ${ }^{[71]}$ synthesis of secondary amines by one-pot three-step cascade reaction ${ }^{[72]}$ and epoxidation of geraniol, ${ }^{[73]}$ among other studies. ${ }^{[74]}$ 
Amino groups on the aromatic linker are among the preferred substituents to modify MOFs by post-functionalization by performing organic reactions, leading to appended moieties anchored to satellite positions on the MOF lattice. This amino-functionalization can be used, for instance, to attach to the structure metal complexes. In one of these examples, aminofunctionalized UiO-66- $\mathrm{NH}_{2}$ was modified with thiophene-2-carbaldehyde (TC) to form a Schiff base, which was later complexed with $\mathrm{CuCl}_{2}$ to form $\mathrm{UiO}-66-\mathrm{NH}_{2}-\mathrm{TC}-\mathrm{Cu}$ (Figure 6). ${ }^{[75]}$ The amount of $\mathrm{Cu}(\mathrm{II})$ on the material was $0.32 \mathrm{mmol} / \mathrm{g}$ of catalyst as determined by ICP analysis. The catalytic activity of UiO-66- $\mathrm{NH}_{2}-\mathrm{TC}-\mathrm{Cu}$ was checked in the synthesis of benzimidazoles and benzothiazoles by reaction of aldehydes with 1,2-diaminobenzene or 2aminothiophenol (Scheme 12). The reaction between 4-chlorobenzaldehyde and 1,2diaminobenzene in the presence of $\mathrm{UiO}-66-\mathrm{NH}_{2}$ and $\mathrm{UiO}-66-\mathrm{NH}_{2}-\mathrm{TC}$ at the same reaction time resulted in 25 and $20 \%$ yields at $50{ }^{\circ} \mathrm{C}$ in ethyl acetate as solvent. In contrast, UiO-66- $\mathrm{NH}_{2}-$ TC-Cu afforded $91 \%$ yield of the desired product under identical conditions with a TOF value of $910 \mathrm{~h}^{-1}$. Similarly, the use of UiO-66- $\mathrm{NH}_{2}-\mathrm{TC}-\mathrm{Cu}$ catalyst provided $92 \%$ yield (TOF: 1150 $\mathrm{h}^{-1}$ ) of benzothiazole for the reaction between 4-chlorobenzaldehyde with 2-aminothiophenol at room temperature. This catalyst was used to synthesize a series of benzimidazole and benzothiazole derivatives under mild reaction conditions. UiO-66- $\mathrm{NH}_{2}-\mathrm{TC}-\mathrm{Cu}$ could be reused for five consecutive cycles in the synthesis of 2-(4-chlorophenyl)benzothiazole without considerable reduction in its activity. The XRD patterns indicated that the crystalline UiO-66$\mathrm{NH}_{2}$ structure was not altered after five cycles. 


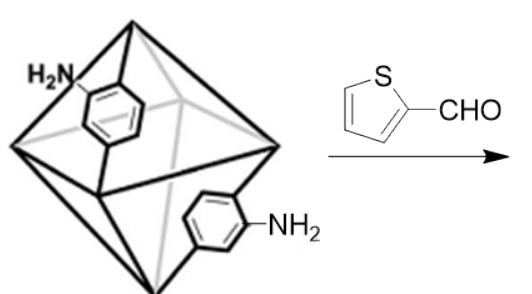

UiO-66- $\mathrm{NH}_{2}$

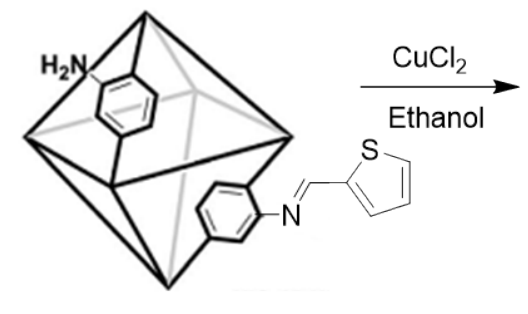

UiO-66- $\mathrm{NH}_{2}-\mathrm{TC}$

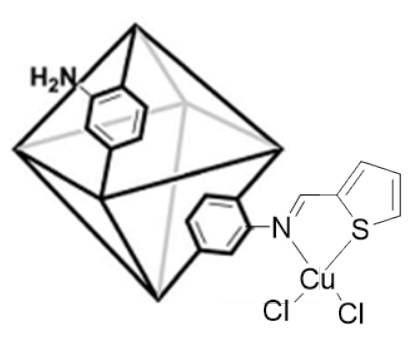

UiO-66- $\mathrm{NH}_{2}-\mathrm{TC}-\mathrm{Cu}$

Figure 6. Preparation procedure of $\mathrm{UiO}-66-\mathrm{NH}_{2}-\mathrm{TC}-\mathrm{Cu}$ catalyst.

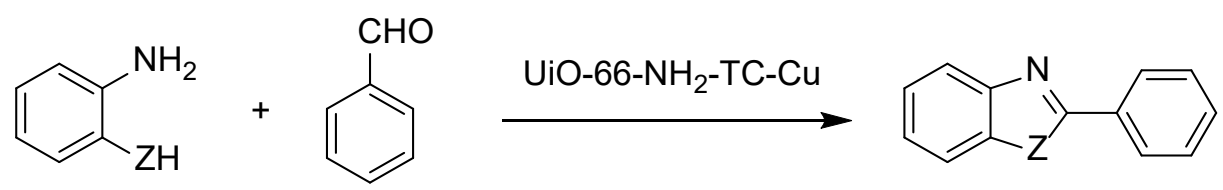

$\mathrm{Z}=\mathrm{NH}, \mathrm{S}$

Scheme 12. Synthesis of benzimidazole and benzothiazole using UiO-66- $\mathrm{NH}_{2}-\mathrm{TC}-\mathrm{Cu}$ as catalyst.

The same strategy starting from UiO-66- $\mathrm{NH}_{2}$ and post-functionalization with salicylaldehyde to afford a Schiff-base has also been used to determine the influence of the $\mathrm{Cu}^{2+}$ precursor salt and the ligands introduced on the $\mathrm{Cu}^{2+}$-Schiff base complex on the catalytic activity for the selective aerobic oxidation of benzyl alcohol assisted by TEMPO. ${ }^{[76]}$ The $\mathrm{Cu}$ contents in UiO-66-SA-CuCl 2 ( $\mathrm{SA}$ : salicylaldehyde), UiO-66-SA-Cu(NO$)_{2}$ and UiO-66-SA$\mathrm{Cu}(\mathrm{OAc})_{2}$ were $5.25,4.08$ and 3.27 wt $\%$, respectively. UiO-66-SA-Cu(NO$)_{2}$ as catalyst exhibited $83 \%$ conversion of the benzyl alcohol with $99 \%$ selectivity of benzaldehyde in the aerobic oxidation of benzyl alcohol using TEMPO as cocatalysts with $\mathrm{NaHCO}_{3}$ as base in acetonitrile at $60^{\circ} \mathrm{C}$. Under identical conditions, UiO-66-SA-Cu(OAc) $)_{2}$ and UiO-66-SA-CuCl 2 resulted in 68 and $99 \%$ conversions of benzyl alcohol, respectively, with $99 \%$ selectivity in both cases. UiO-66-SA-CuCl 2 maintained its activity for five runs. Furthermore, powder XRD and FT-IR data of five times recycled UiO-66-SA-CuCl 2 were identical to those of the fresh sample, thus, suggesting the stability of this catalyst. 
In another precedent, the same research group has adopted a similar strategy to anchor $\mathrm{MoO}_{2}$ (acac) (acac: acetylacetonate) over UiO-66- $\mathrm{NH}_{2}$ to obtain a series of catalysts, namely, UiO-66- $\mathrm{NH}_{2}-\mathrm{SA}-\mathrm{Mo}$ and $\mathrm{UiO}-66-\mathrm{NH}_{2}-\mathrm{TC}-\mathrm{Mo}$ and their activity was examined in the epoxidation of olefins using $t$-butylhydroperoxide (TBHP) as oxidant. ${ }^{[77]}$ Under the optimized reaction conditions, UiO-66- $\mathrm{NH}_{2}-\mathrm{SA}-\mathrm{Mo}$ and UiO-66-- $\mathrm{NH}_{2}-\mathrm{TC}-\mathrm{Mo}$ afforded 97 (TOF: $61 \mathrm{~h}^{-1}$ ) and $94 \%$ yield of epoxide, respectively, for the cyclooctene epoxidation with TBHP, the former catalyst reacting also somewhat faster. UiO-66- $\mathrm{NH}_{2}-\mathrm{SA}-\mathrm{Mo}$ was reused four consecutive cycles without any leaching of Mo after the second run. In contrast, UiO-66- $\mathrm{NH}_{2}-$ TC-Mo showed 5 and $2 \%$ of molybdenum leaching in the two first runs and no further Mo was detected in the third run.

Other group has also similarly used salicylaldehyde to attach Mo to be employed as alkene epoxidation catalyst. Thus, a series of four materials was synthesised including the fully amino-functionalised UiOs (UiO-66- $\mathrm{NH}_{2}$ and $\left.\mathrm{UiO}-67-\mathrm{NH}_{2}\right)$ as well as mixed linkers UiOs where only $1 / 6$ of the linkers contain the $-\mathrm{NH}_{2}$ groups (termed here as UiO-66 mixed). These four solids were post-synthetically modified with salicylaldehyde to form a Schiff base-like ligand which later is used to anchor a molybdenum complex (Figure 7). ${ }^{[78]}$ The activity of these catalysts was studied in the oxidation of olefins using TBHP as oxidant. The Mo content in UiO-NH2-SA-Mo composites was $8.48 \%$ for UiO-66- $\mathrm{NH}_{2}, 5.69 \%$ for UiO-66-mixed, $3.23 \%$ for UiO-67- $\mathrm{NH}_{2}$ and $2.43 \%$ for UiO-67-mixed MOFs. In general, the activity of UiO-66/67$\mathrm{NH}_{2}$-SA-Mo mixed was much higher than those of UiO-66/67- $\mathrm{NH}_{2}-\mathrm{SA}-\mathrm{Mo}$ in the epoxidation of cyclooctene using TBHP as oxidant at $50{ }^{\circ} \mathrm{C}$. For instance, the conversion of cyclooctene was under identical conditions 63 and $94 \%$ for UiO-66- $\mathrm{NH}_{2}-\mathrm{SA}-\mathrm{Mo}$ and UiO-66-NH $\mathrm{N}_{2}-\mathrm{SA}-$ Mo mixed as catalysts, respectively. On the other hand, it was found that the catalytic activity also depends strongly on the effective pore size of the MOF material, owing to diffusion limitations of substrate, product and oxidant. For this reason, UiO-67- $\mathrm{NH}_{2}-\mathrm{SA}-\mathrm{Mo}$ mixed 


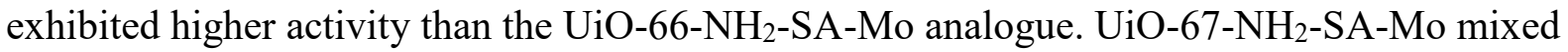
was used ten consecutive cycles without any decay in its activity. On the other hand, comparison of the powder XRD patterns of fresh and reused catalyst indicates that the framework has remained intact during recycling.

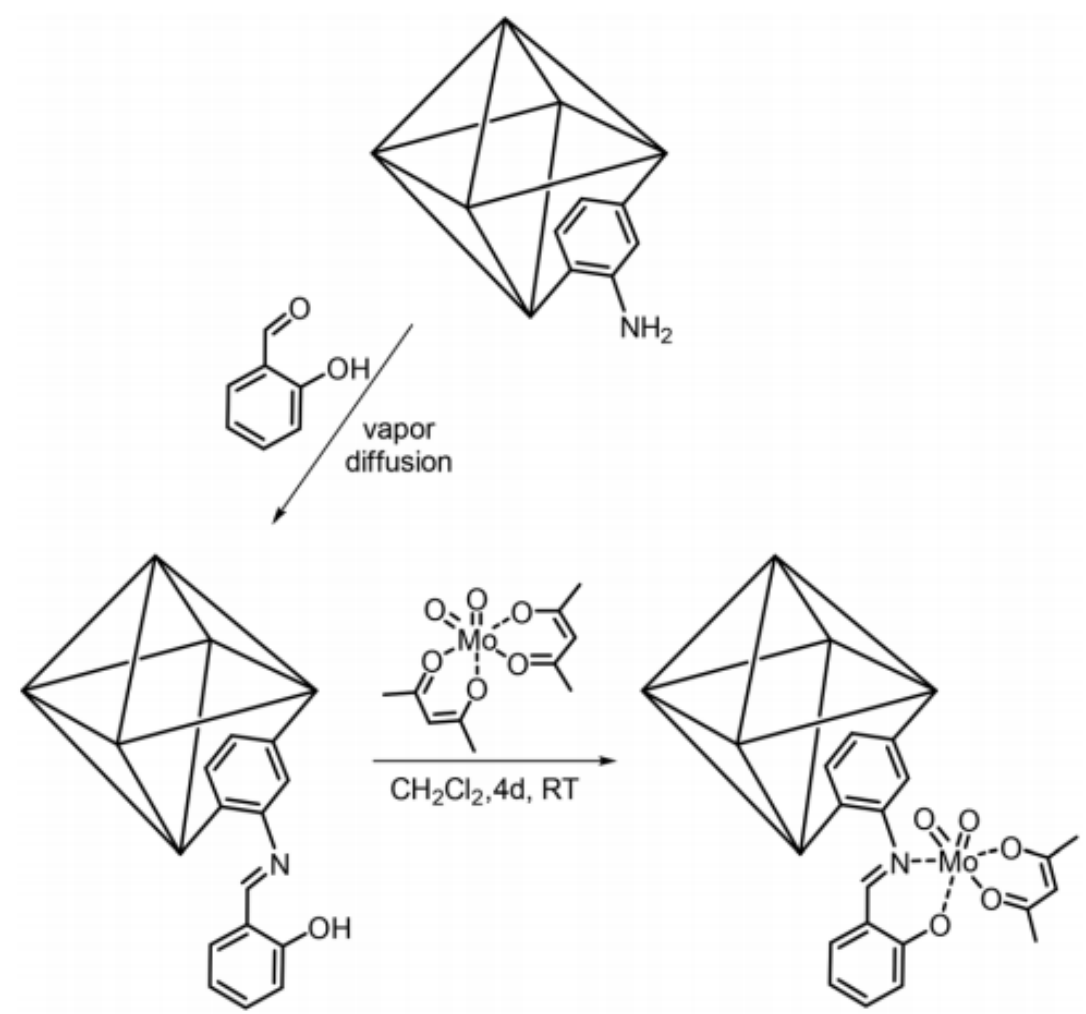

Figure 7. Post-functionalization route of $\mathrm{UiO}-66 / 67-\mathrm{NH}_{2} \mathrm{MOFs}$ with salicylaldehyde and $\left[\mathrm{MoO}_{2}(\mathrm{acac})_{2}\right]$. Reproduced with permission from ref [78]. Copyright 2015 Royal Society of

\section{Chemistry.}

\subsection{Other functionalized BDC as catalysts}

The incorporation of 2,3-dimercaptoterephthalate (thiocatecholate, TCAT) into a highly robust UiO-66 has been carried out by post-synthetic exchange and the thiocatecholate moiety metallated later with $\mathrm{Pd}(\mathrm{OAc})_{2}$ to provide UiO-66-Pd-TCAT (Figure 8). ${ }^{[79]}$ Attempts to introduce TCAT as linker directly during the synthesis of the UiO-66 type material met with failure. The catalytic activity of UiO-66-Pd-TCAT was examined in the regioselective $\mathrm{C}-\mathrm{H}$ 
oxidation of benzo[h]quinoline using iodobenzene diacetate $\left[\mathrm{PhI}(\mathrm{OAc})_{2}\right]$ as oxidant. A quantitative yield of methoxy functionalized benzo[h]quinoline (See Scheme 13) was achieved using UiO-66-Pd-TCAT ( $5 \mathrm{~mol} \%$ in $\mathrm{Pd}$ ) as solid catalyst at $60^{\circ} \mathrm{C}$. In contrast, pristine UiO-66 and UiO-66-TCAT (in the absence of Pd) resulted in no conversion under identical conditions. The reaction was heterogeneous in nature and $<0.1 \mathrm{ppm}$ Pd was found in leaching experiments. UiO-66-Pd-TCAT was recycled five times without a significant decrease in the product yield. This enhanced activity was due to the strong metal-thiocatecholato bond and to the site isolation of active $\mathrm{Pd}^{2+}$ ions in to the UiO-66-Pd-TCAT pores.

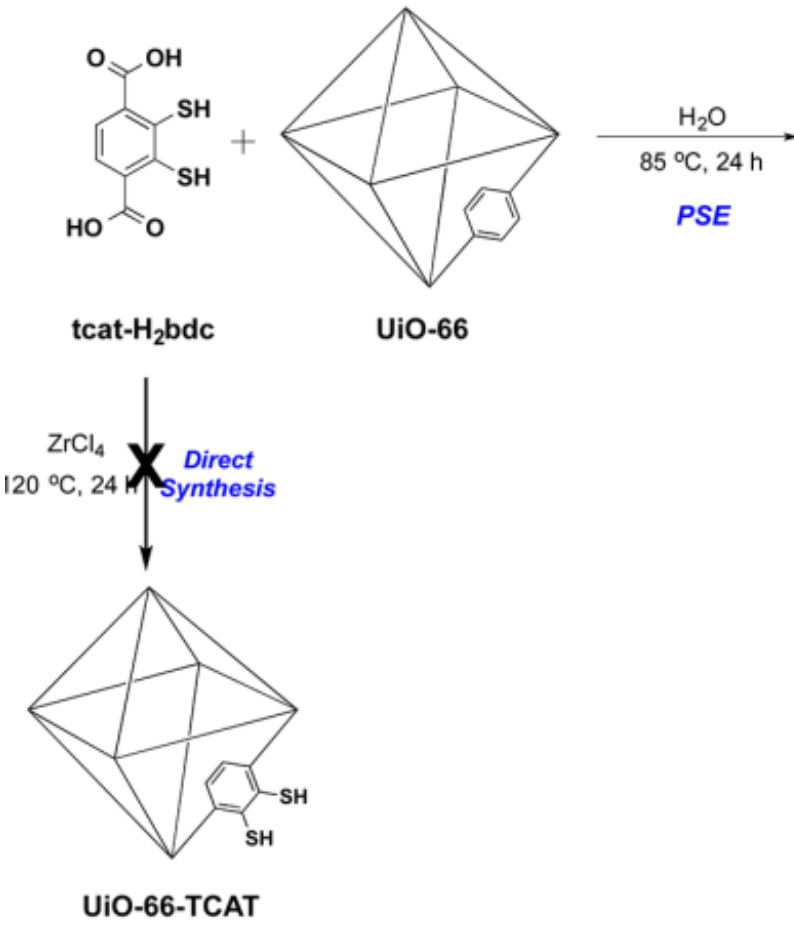

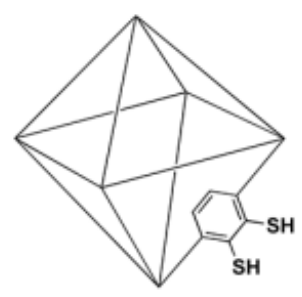

UIO-66-TCAT

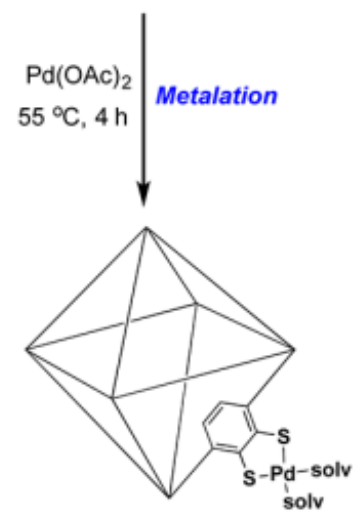

UIO-66-PdTCAT

Catalytically Acitve

Figure 8. Synthesis of UiO-66-TCAT and UiO-66-Pd-TCAT. Reproduced with permission from ref [79]. Copyright 2015 American Chemical Society.<smiles>C1=CC2=CC=Cc3cccc2c3C=C1</smiles>

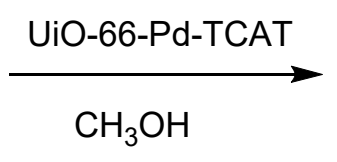<smiles>COc1cccc2ccc3cccnc3c12</smiles>

Scheme 13. UiO-66-Pd-TACT catalyzed regioselective C-H oxidation of benzo[h]quinoline. 
In another work, an isolated metal-monocatecholato moiety in UiO-66 MOF was obtained by two different post-synthetic strategies, namely, post-synthetic deprotection and post-synthetic exchange (See Figure 9 for the synthetic routes). It was proved that postsynthetic exchange is a more facile and efficient functionalization approach compared to postsynthetic deprotection to access the wanted catecholato MOFs that could not be directly synthesized under solvothermal conditions. Metallation of the catechol functionality residing in the MOF pores resulted in unprecedented Cr-monocatecholato species (UiO-66-CrCAT). This catalyst exhibited quantitative yield to 2-heptanone from 2-heptanol oxidation at $70{ }^{\circ} \mathrm{C}$ using TBHP as oxidant. ${ }^{[80]}$ The same oxidation reaction was completed in one third of the time using UiO-66-CrCAT catalyst under identical conditions in the absence of solvent. In contrast, UiO-66 and UiO-66-CAT resulted in $8 \%$ and $12 \%$ yields of 2-heptanone, respectively. The activity of UiO-66-CrCAT for the oxidation of 2-heptanol was retained for five runs. 


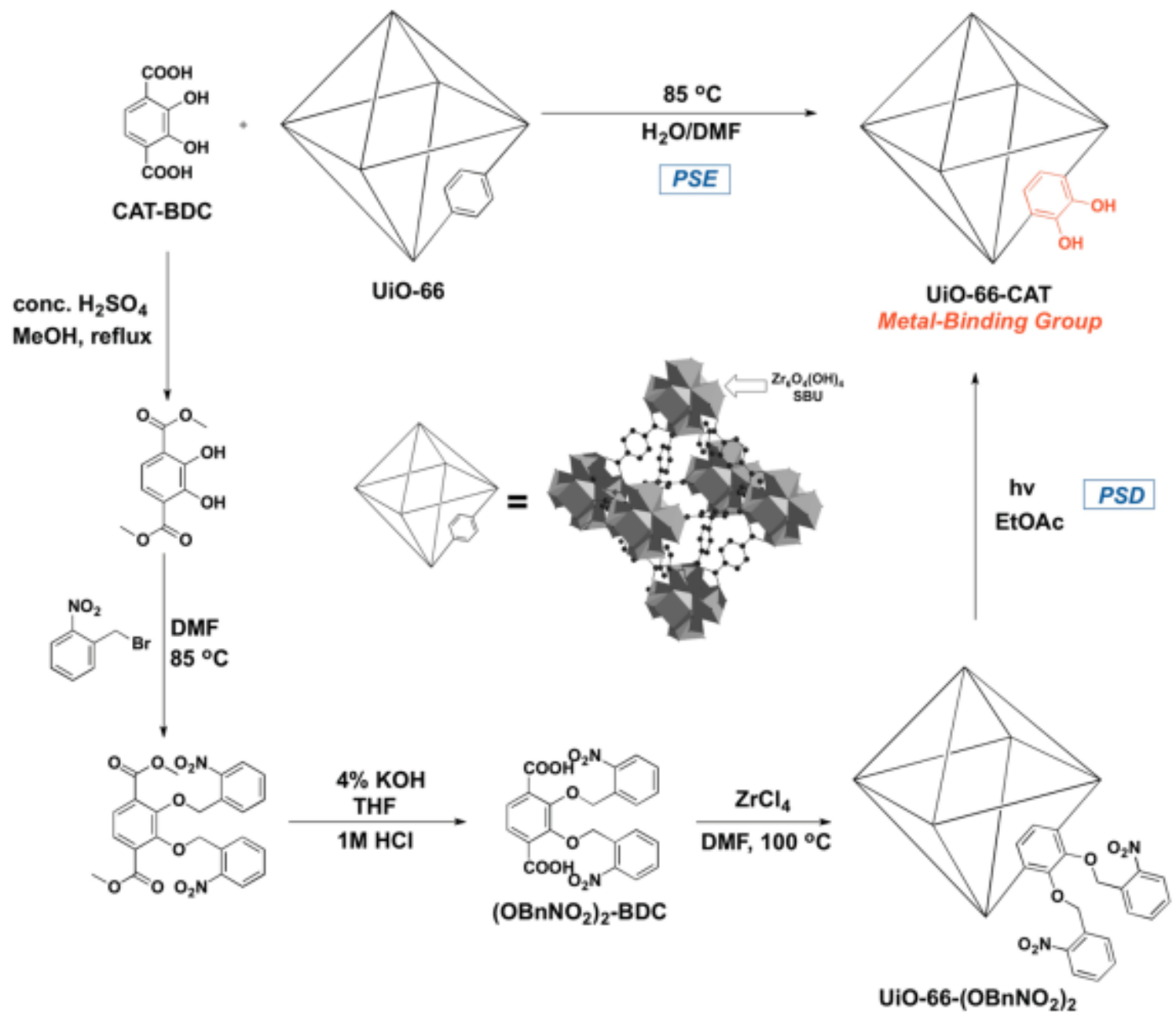

Figure 9. Synthesis of UiO-66-CAT via post-synthetic exchange and deprotection methods. Reproduced with permission from ref [80]. Copyright 2014 American Chemical Society.

Recently, a series of TEMPO-appended on UiO-66 and UiO-67 MOFs (Figure 10) has been prepared containing different proportions of TEMPO and their activity for the aerobic oxidation of alcohols under mild reaction conditions was studied. ${ }^{[81]}$ The aerobic oxidation of benzyl alcohol to benzaldehyde resulted in quantitative yield with UiO-67-TEMPO(38 \%) at $25{ }^{\circ} \mathrm{C}$ in acetonitrile, dioxane, and 1,2-dichloroethane. Interestingly, the use of UiO-67TEMPO $(38 \%)$ as catalyst afforded $48 \%$ yield at $0{ }^{\circ} \mathrm{C}$. Hence, UiO-66 type catalyst offers additional advantages for promoting the oxidation of thermally sensitive substrates. The catalyst was reused up to three times. After the first run, the material retained its crystallinity, but it partially changed the nature of active sites, which turn into a mixture of free oxyl radicals 
and oxidized oxoammonium cations as evidenced from EPR and ATR-IR spectroscopic data. A marked decrease in the activity was noticed after the second run, which in this case was due to the collapse of the crystalline structure.
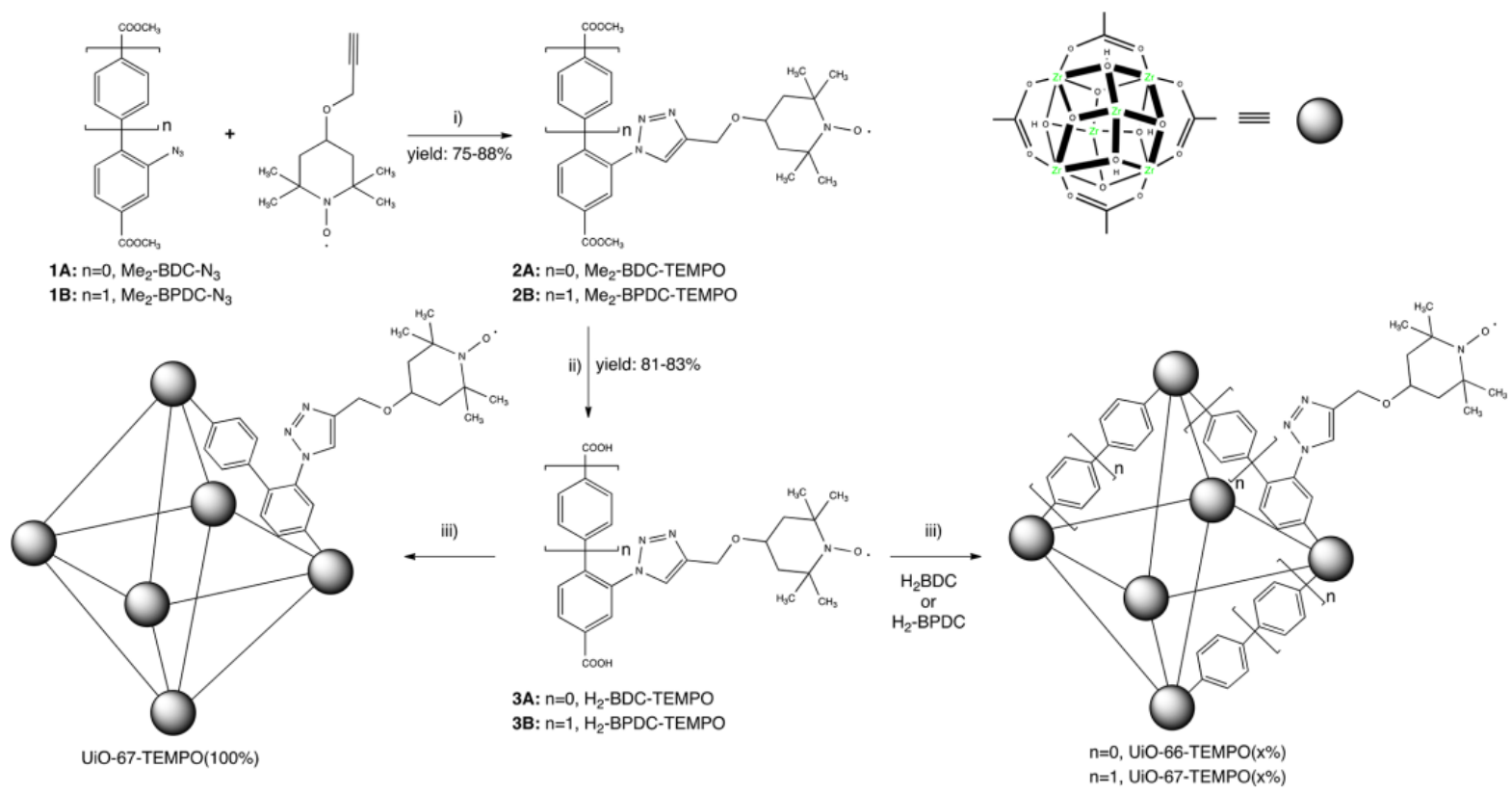

Figure 10. Synthesis of UiO-66-TEMPO(x\%) and UiO-67-TEMPO(x\%) materials. Reagents and conditions: (i) $\mathrm{CuI} \cdot \mathrm{P}(\mathrm{OEt})_{3}$, diisopropylethylamine, $\mathrm{CHCl}_{3}$; (ii) $\mathrm{LiOH}, \mathrm{CH}_{3} \mathrm{OH} / \mathrm{H}_{2} \mathrm{O}, 50$ ${ }^{\circ} \mathrm{C}$; and (iii) $\mathrm{ZrCl}_{4}, \mathrm{HCl}_{\mathrm{aq}}$, DMF, $80{ }^{\circ} \mathrm{C}$. Reproduced with permission from ref [81]. Copyright 2017 American Chemical Society.

A series of functionalized isostructural UiO-66 MOFs were synthesised bearing different function groups in the linker (UiO-66-X; $\mathrm{X}=\mathrm{H}, \mathrm{NH}_{2}, \mathrm{NO}_{2}, \mathrm{Br}, \mathrm{Cl}$ ) and their activity was tested in the ring opening of epoxide by methanol (Scheme 14). ${ }^{[82]}$ The initial reaction rate observed at $50{ }^{\circ} \mathrm{C}$ for UiO-66-H, UiO-66- $\mathrm{NO}_{2}, \mathrm{UiO}-66-\mathrm{NH}_{2}, \mathrm{UiO}-66-\mathrm{Br}$ and UiO-66-Cl were $9.6,20,50.1,143.1$ and $128.8\left(\mathrm{~mol}^{-1}\right) \times 10^{-6}$, respectively, which is an increase in the initial reaction rate from $\mathrm{UiO}-66-\mathrm{H}$ to $\mathrm{UiO}-66-\mathrm{Br}$, over one order of magnitude. The influence of the electron withdrawing effect of the substituent on the observed catalytic activity does not fit exclusively with the increase in the Lewis acid strength on the $\mathrm{Zr}^{4+}$ ions and it seems that this effect can be overlapped with the extent of defects on the structure due to the possible different 
crystallinity of the substituted UiO-66-X. Also, UiO-66-Br exhibits a wide scope, but, however, its activity mainly depends on the molecular dimension of epoxide and nucleophile. The catalyst stability was evaluated by performing a series of consecutive runs using UiO-66-Br and observing a significant deactivation during reuse tests, as determined by a decrease in both the initial reaction rate and the conversion at final time. Powder XRD patterns of the reused catalyst indicated that the crystalline structure of the two times used sample is largely preserved and the origin of the deactivation was later confirmed to be due to the product adsorption over the solid catalyst.

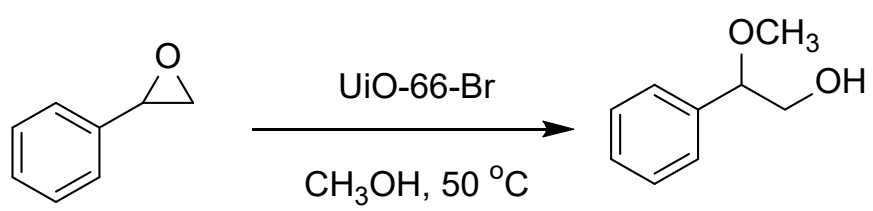

Scheme 14. Ring opening reaction of styrene oxide by methanol using UiO-66-Br as a heterogeneous catalyst.

\section{UiO-66 as host}

Besides playing an active role, UiO-66 can also be used as high surface area support to include within the pores or deposit on the external surface of the crystallites the active species, frequently metal NPs, but also other guests. The main advantage of this strategy is the mechanical hindrance imposed by the UiO-66 lattice to the growth of metal NPs. Sintering and growth of the NPs is one of the general deactivation pathways for this type of catalyst and this aggregation can be impeded by the encapsulation within a confined space and by guest-host interactions. ${ }^{\left[83,{ }^{84]}\right.}$ In the following paragraphs, it has been ordered according to the guests.

\subsection{Pt NPs}

Highly monodispersed Pt NPs of small size were confined in the cavities of UiO-66$\mathrm{NH}_{2}$ at 10.7 wt $\% \mathrm{Pt}$ loading. The effect of confinement of Pt NPs within the cavities was assessed by comparing the catalytic performance of Pt NPs supported on the external surface 
of the UiO-66- $\mathrm{NH}_{2}$ in the chemoselective hydrogenation of cinnamaldehyde. ${ }^{[85]}$ The use of 10.7\% $\quad \mathrm{Pt} @$ UiO-66- $\mathrm{NH}_{2} \quad(\mathrm{Pt}$ size $1.2 \mathrm{~nm})$ catalyst afforded $85.9 \quad \%$ conversion of cinnamaldehyde with $87.9 \%$ selectivity to cinnamyl alcohol at room temperature. In contrast, 4.2\% Pt@UiO-66- $\mathrm{NH}_{2}(\mathrm{Pt}$ size $1.7 \mathrm{~nm})$ resulted in considerably lower conversion of $52.2 \%$ and selectivity of $71.6 \%$ at similar reaction time. Also, a commercial catalyst $5 \% \mathrm{Pt} / \mathrm{C}$ gave a much lower selectivity of $71.9 \%$ at $41.3 \%$ conversion under identical conditions. The $\mathrm{Pt} @$ UiO-66- $\mathrm{NH}_{2}$ catalyst was recycled ten times without any loss in its activity and selectivity with a total TON value of 10900 .

Ultrasmall Pt NPs of $1.2 \mathrm{~nm}$ average particle size were encapsulated in aminefunctionalized UiO-66- $\mathrm{NH}_{2}$ to give $\mathrm{Pt} @ \mathrm{UiO}-66-\mathrm{NH}_{2}$ that acts as a multifunctional catalyst, exhibiting activity in the one-pot tandem synthesis of nitrones from benzaldehyde (Scheme 15) ${ }^{[86]}$ The observed catalytic activity was due to the cooperative interplay among the selective hydrogenation ability provided by the Pt NPs and the bifunctional Lewis acidity-basicity afforded by UiO-66- $\mathrm{NH}_{2}$. $\mathrm{Pt} @ \mathrm{UiO}-66-\mathrm{NH}_{2}$ provides $99 \%$ conversion of benzaldehyde with $97 \%$ selectivity for nitrone formation in toluene. On the other hand, $\mathrm{Pt} @$ UiO-66- $\mathrm{NH}_{2}$ also gave $99 \%$ conversion with $98 \%$ selectivity of nitrone using nitromethane as medium. To assess the role of the amino groups stabilizing the nanometric Pt NPs, Pt@UiO-66 lacking amino groups was prepared with a similar Pt size as determined by TEM, but its use as catalyst resulted in significantly lower conversion (28\%) and the major product formed was benzyl alcohol in moderate selectivity (53\%). These data illustrate the crucial role of $-\mathrm{NH}_{2}$ in achieving high selectivity to nitrone in the tandem reaction, inhibiting the direct hydrogenation of benzaldehyde. Furthermore, $\mathrm{Pt} / \mathrm{C}$ led also to low selectivity for the nitrone product (23\%) along with the formation of $\beta$-nitrostyrene $(25 \%)$ as the major product. 


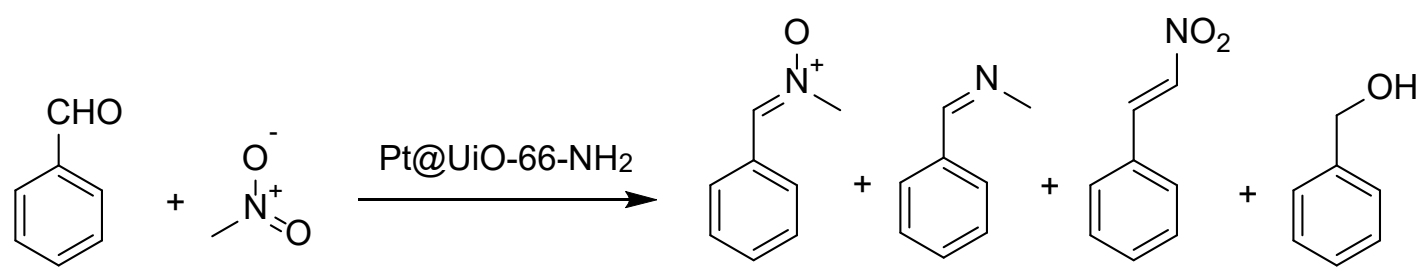

Scheme 15. Nitrone synthesis catalyzed by $\mathrm{Pt} @ \mathrm{UiO}-66-\mathrm{NH}_{2}$ through tandem reaction of benzaldehyde with nitromethane.

In another example, Pt NPs stabilized by polyvinyl pyrrolidine $(2.9 \mathrm{~nm})$ were loaded on UiO-66 MOFs. The resulting Pt@UiO-66 was tested as catalyst for the liquid-phase hydrogenation of 1-hexene, cyclooctene, trans-stilbene, cis-stilbene, triphenylethylene, and tetraphenylethylene. ${ }^{[87]}$ The conversion rate of reactants decreased as the molecular size of these alkenes increased (Figure 11). Pt@UiO-66 showed $100 \%$ conversion of 1-hexene (molecular size $2.5 \AA$ ), in agreement with the assumption that 1-hexene can diffuse quickly inside the pores of UiO-66. The conversion reached by Pt@UiO-66 for hydrogenation of cyclooctene (5.5 $\AA$ ), trans-stilbene (5.6 $)$ ) and triphenylethylene (5.8 $\AA$ ) was $65.99 \%, 35 \%$ and $8 \%$ at the same time. These values follow the order expected for a decrease in reactant diffusion inside the MOF matrix. Therefore, it seems that diffusion is the main factor controlling alkene reactivity when using Pt@UiO-66. In good accordance with this assumption, Pt@UiO-66 showed no activity for the hydrogenation of tetraphenylethylene (6.7 ̊). This lack of catalytic activity is consistent with the pore size for UiO-66 (6 $\AA)$. These catalytic results also suggest the absence of Pt NPs on the external surface of the UiO-66 crystallites. On the other hand, Pt NPs supported on carbon nanotubes exhibited much less discriminating catalytic activity towards the hydrogenation of the same substrates, reflecting in the case of carbon nanotubes supported Pt NPs a slight decrease in catalytic activity as consequence only of the steric encumbrance of the $\mathrm{C}=\mathrm{C}$ due to the increasing substitution. In this way, the percentage of alkene conversion for Pt NPs supported on carbon nanotubes was different to that observed for Pt@UiO-66 reaching values for 1-hexene (100\%), cyclooctene (100 \%), cis-stilbene (100 
$\%)$, trans-stilbene (100\%), triphenylethylene (89\%), and tetraphenylethylene (18\%) under identical conditions. The Pt@UiO-66 catalyst was recycled for 1-hexene hydrogenation in three consecutive runs. The porosity of UiO-66 was preserved after catalytic reaction and no significant structural degradation was detected from the XRD patterns.

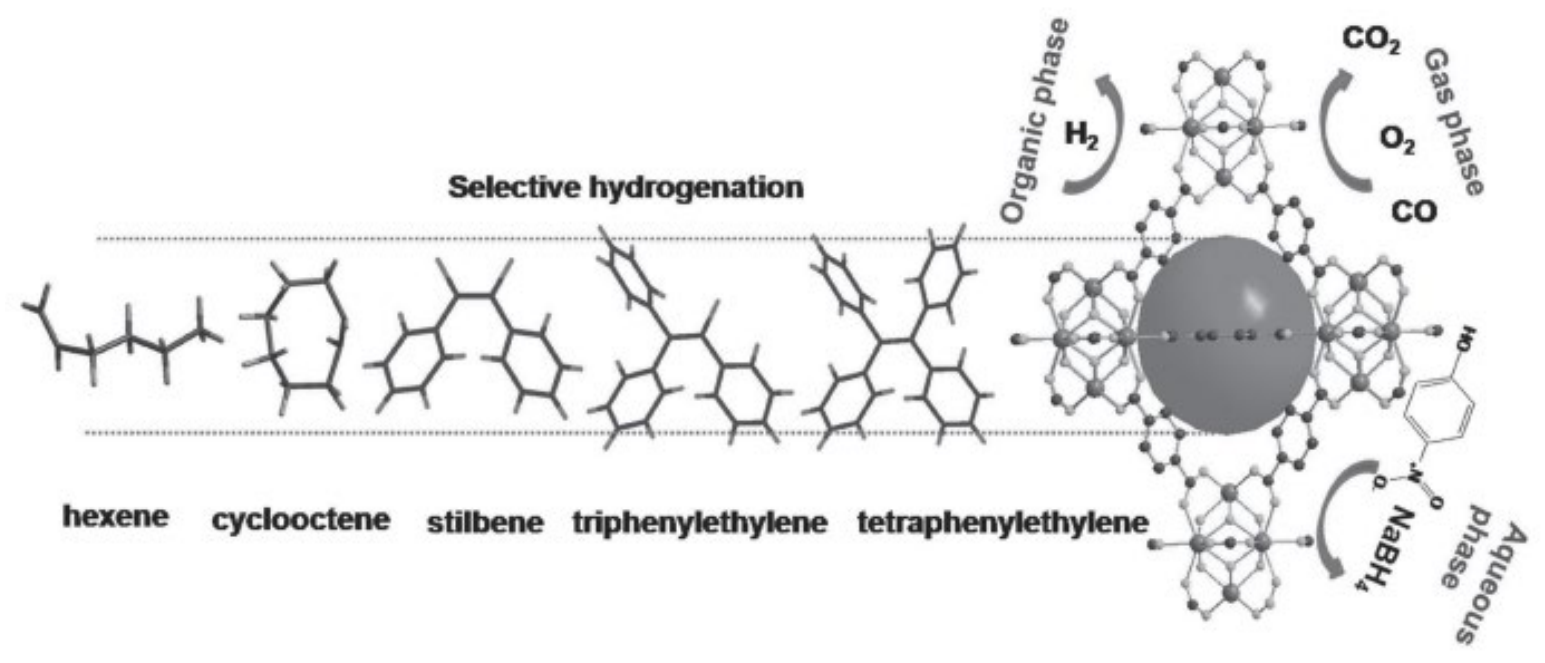

UiO-66 pore aperture

Figure 11. Size selective hydrogenation by Pt@UiO-66 due to the internal location of the Pt NPs. Reproduced with permission from ref.[87] Copyright 2014 from Wiley.

One interesting aspect that has remained up to now almost unexploited is how the chemical environment and polarity provided by the linker can influence the catalytic activity, and even the selectivity, of the metal NPs embedded in UiO-66. In one of the scarce studies on this issue, UiO-66 was synthesised with two organic linkers with different functional groups, namely, sulfonic acid $\left(-\mathrm{SO}_{3} \mathrm{H}, \mathrm{S}\right)$ and ammonium ion $\left(-\mathrm{NH}_{3}{ }^{+}, \mathrm{N}\right)$. These substituents were selected as strong and weak acids, respectively. Subsequently, Pt NPs $(2.5 \mathrm{~nm})$ were incorporated on these MOFs to obtain a series of Pt NPs embedded in UiO-66 (Pt@UiO-66). ${ }^{[88]}$ The catalytic activity of these MOFs in where the Pt NPs experience different surroundings was studied for the gas-phase conversion of methylcyclopentane (MCP) to its acyclic isomers, olefins, cyclohexane, and benzene. Pt@UiO-66-S exhibited in the highest selectivity to $\mathrm{C}_{6}$ cyclic products $(62.4 \%$ and $28.6 \%$ for cyclohexane and benzene, respectively), acyclic 
isomers being not observed in this catalyst (Figure 12). Interestingly, catalytic activity of Pt@UiO-66-S was two-fold higher relative to the non-functionalized parent Pt@UiO-66 material. On the other hand, Pt@UiO-66-N exhibited a lower selectivity for C6-cyclic products $(<50 \%)$, increasing the selectivity to acyclic isomers to $38.6 \%$ (Figure 12 ). Interestingly, the product selectivity of $\mathrm{Pt} @$ UiO-66-SN containing both $\mathrm{S}$ and $\mathrm{N}$ functional groups was different than those exhibited by any of the two Pd@UiO-X having single linker. No cyclohexane was formed for Pt/UiO-66-SN, benzene being the dominant product accompanied by olefins and acyclic isomers as minor products. All Pt@UiO-66-X catalysts with different substituents on the BDC linker maintained their crystal structure and particle morphology without undergoing deactivation during the course of a reaction. These results nicely illustrate that the intrinsic activity of Pt NPs as hydrogenating/dehydrogenative catalysts can be tuned and directed towards specific pathways by the presence of adjacent functional groups. It will be, however, still necessary some rationalization of the selectivity as a function of the ligand. It may very likely be that the cooperation of sites with different nature and activity could open new reaction pathways. Thus, the combination of metal NPs and MOF sites that could lead to UiO-66 specifically designed for a specific activity. 
A
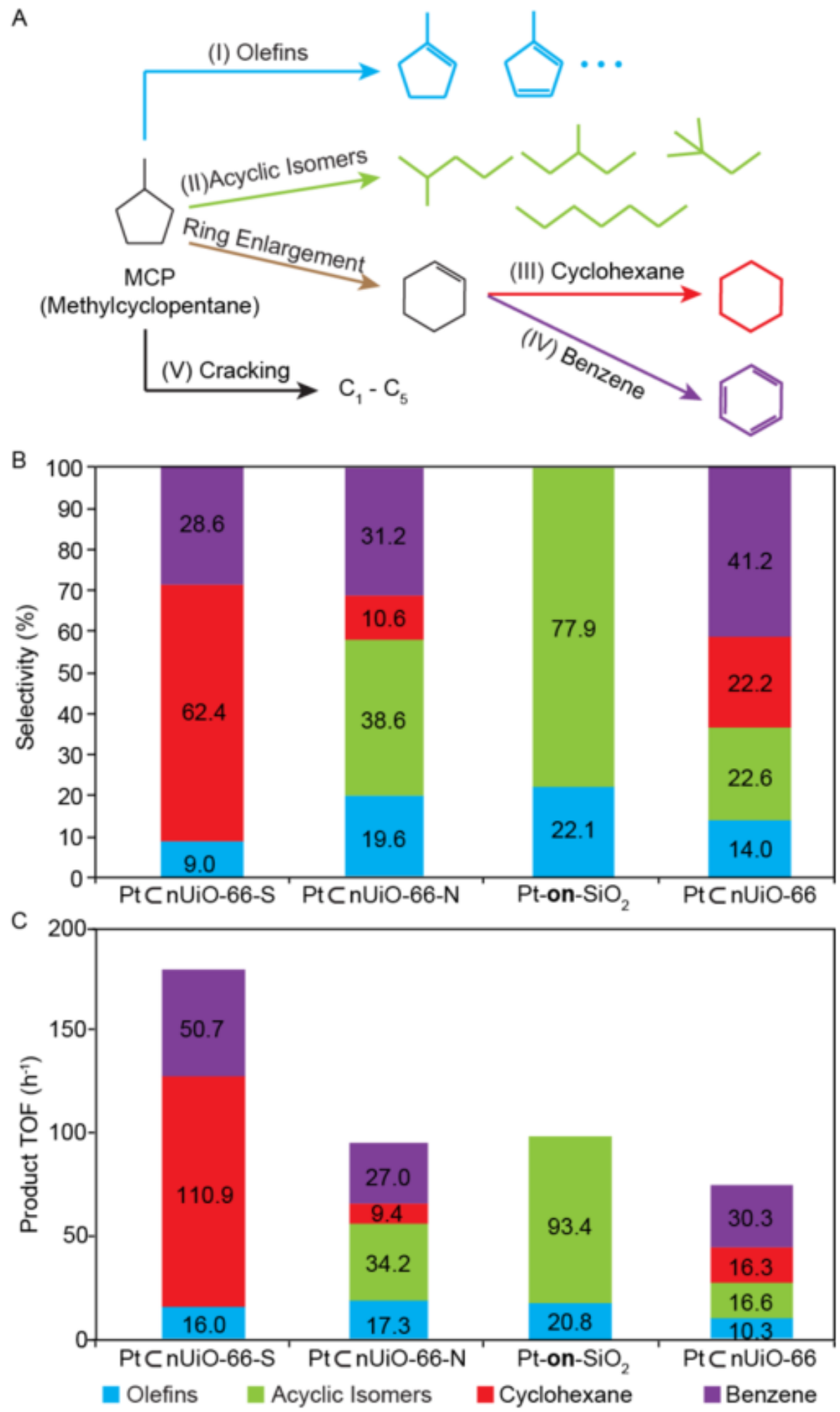

Figure 12. (A) Possible reaction pathways occurring in the reaction of MCP, (B) product selectivity, and (C) TOF, $\mathrm{h}^{-1}$ obtained at $150{ }^{\circ} \mathrm{C}$ over Pt@UiO-66-S and N, Pt@UiO-66, and 
Pt-on-SiO 2 . Reproduced with permission from ref [88]. Copyright 2015 American Chemical

Society.

\subsection{Pd NPs}

Pd exhibits general catalytic activity in oxidation, reduction and cross-coupling reactions. In one of the examples of Pd NPs embedded in MOFs, Pd NPs were supported both on $\mathrm{UiO}-66-\mathrm{NH}_{2}$ and UiO-66 and their activity was tested in the tandem oxidation-acetalization reactions of benzyl alcohol and ethylene glycol. ${ }^{[89]}$ The activity of 2 wt\% Pd@UiO-66- $\mathrm{NH}_{2}$ (Pd size $1.2 \mathrm{~nm}$ ) was $99.9 \%$ conversion of benzyl alcohol with $99.9 \%$ selectivity to benzaldehyde ethylene acetal under $0.1 \mathrm{MPa} \mathrm{O}_{2}$ at $90{ }^{\circ} \mathrm{C}$ in cyclohexane. In contrast, the use of $5 \mathrm{wt} \% \mathrm{Pd} / \mathrm{C}$ exhibited $99.9 \%$ conversion of benzyl alcohol with $59.7 \%$ of acetal, while with 1.9 wt \% Pd@UiO-66 as catalyst showed $91 \%$ conversion of benzyl alcohol with 95 \% selectivity to acetal under identical conditions, which are slightly lower values than the activity shown by $\mathrm{Pd} @ \mathrm{UiO}-66-\mathrm{NH}_{2}$. On the other hand, UiO-66- $\mathrm{NH}_{2}$ gave $1.5 \%$ conversion of benzyl alcohol, which confirmed that the oxidation of benzyl alcohol to benzaldehyde is catalyzed by Pd NPs. Furthermore, the activity of UiO-66- $\mathrm{NH}_{2}$ reached to $99.9 \%$ conversion and $99.9 \%$ selectivity in the acetalization reaction using benzaldehyde and ethylene glycol, which shows its role as acid catalyst in acetalization reaction. These data confirm that the both Pd NPs and Lewis acid sites on MOFs are essential for the efficient tandem oxidation-acetalization reaction. The Pd@UiO-66- $\mathrm{NH}_{2}$ catalyst was reused for five cycles with no decay in its activity.

Later, the catalytic activity of Pd NPs was reported to be influenced by the chemical environment provided by the linker in the aerobic reaction of benzaldehyde with ethylene glycol. ${ }^{[90]}$ For instance, Pd NPs were encapsulated in isoreticular MOFs of UiO-66-X (Pd@UiO-66-X, X= H, NH $2, \mathrm{OMe}$ ) and it was observed that $\mathrm{Pd} @$ UiO-66- $\mathrm{NH}_{2}$ favours the formation of acetal, while Pd@UiO-66 and Pd@UiO-66-OMe lead to a higher selectivity to the ester (Figure 13). Furthermore, the interaction between Pd NP and the amino groups was 
revealed by DRIFTS studies that show that $\mathrm{NH}_{2}$ groups coordinate to the Pd surface and donate electrons to the Pd NPs in $\mathrm{Pd} @ \mathrm{UiO}-66-\mathrm{NH}_{2}$. These $\mathrm{NH}_{2} \ldots \mathrm{Pd}$ interactions decrease the oxidation capability of encapsulated Pd NPs and in this way, favours the high acetal selectivity by $\mathrm{Pd} @ \mathrm{UiO}-66-\mathrm{NH}_{2}$ in the reaction. It seems that DFT calculations corroborate these spectroscopic data by indicating that the Pd NPs interacting with $\mathrm{NH}_{2}$ groups possess higher chemical potential and, thus, weaker oxidation capability than when the interaction of Pd NPs is with $-\mathrm{OCH}_{3}$ groups.

(a)
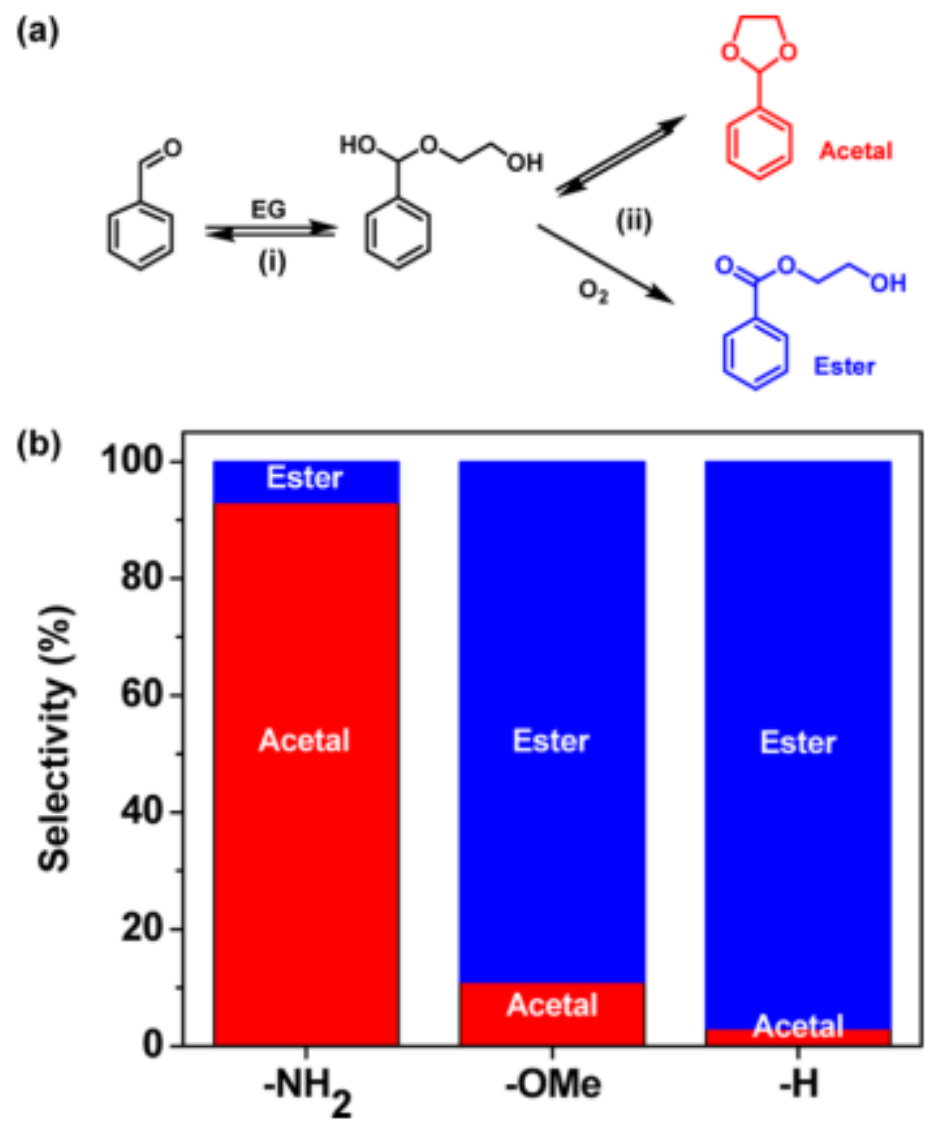

Figure 13. Tandem aerobic oxidation-acetalization between benzaldehyde and ethylene glycol leading to the cyclic ethylene acetal or 2-hydroxyethyl benzoate ester. (b) Different product distribution using $\mathrm{Pd} @ \mathrm{UiO}-66-\mathrm{X}\left(\mathrm{X}=\mathrm{H}, \mathrm{NH}_{2}, \mathrm{OMe}\right)$. Reproduced with permission from ref [90]. Copyright 2016 American Chemical Society.

Pd NPs encapsulated inside UiO-66 and UiO-67 have been prepared by chemical vapour infiltration of (allyl) $\mathrm{Pd}(\mathrm{Cp})$ complex followed by UV light decomposition of the 
complexes adsorbed with the pores. ${ }^{[91]}$ The catalytic activity of $\mathrm{Pd} / \mathrm{C}\left(263.4 \mathrm{~h}^{-1}\right)$ and Pd $298 \mathrm{~K} @$ UiO-66 (298 K refers to the temperature of Pd precursor adsorption) (168.6 $\left.\mathrm{h}^{-1}\right)$ exhibited high hydrogenation rate of acetophenone to 1-phenylethanol at $60{ }^{\circ} \mathrm{C}$ due to the fact that Pd NPs are located at the external surface of the catalyst (Figure 14). In contrast, the catalytic performance of $\mathrm{Pd}_{263 \mathrm{~K}} @ \mathrm{UiO}-66\left(3.2 \mathrm{~h}^{-1}\right)$ in where Pd NPs are located within the lattice was very low due to the diffusion limitations of acetophenone to the internal pores of UiO-66, through the ca. $6 \AA$ triangular pore windows. These catalytic data clearly demonstrate an easy and convenient way to indirectly locate the NPs in MOFs by determining the catalytic activity of the material containing metal NPs with substrates that are not able to diffuse through the MOF pore.

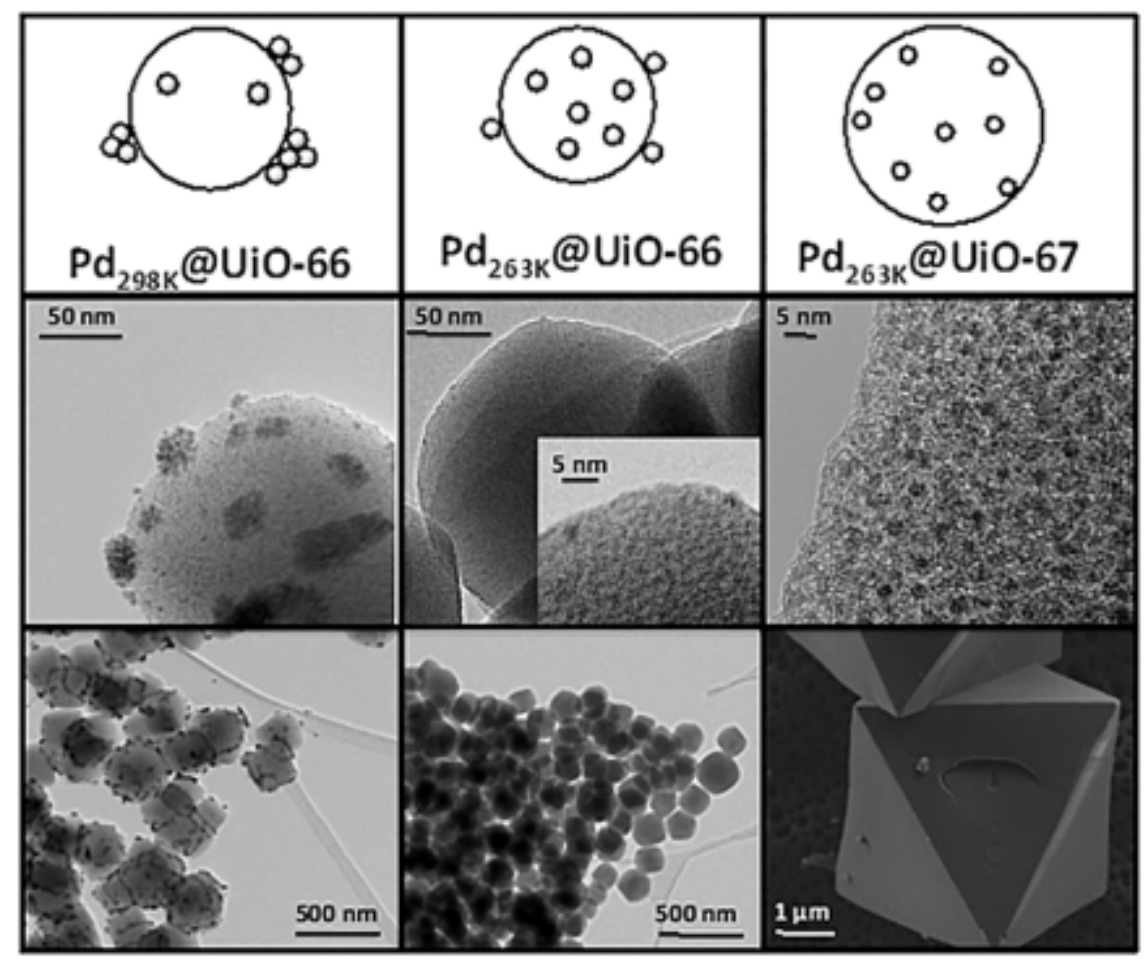

Figure 14. Schematic representation of the location of Pd NPs on the MOF samples depending on the Pd precursor adsorption at different temperature and representative electron microscopy images supporting the external and internal location of the Pd NPs. Reproduced with permission from ref [91]. Copyright 2015 from Wiley. 
Recently, the catalytic activity of Pd@UiO-66 was studied in the hydrogenation of phenol in water (Scheme 16). ${ }^{[92]} \mathrm{Pd} @$ UiO-66 resulted in complete conversion of phenol in increasing time as the reaction temperature decreases in the range from 120 to $60{ }^{\circ} \mathrm{C}$. The reaction rates using $\mathrm{Pd} @ \mathrm{UiO}-66$ catalyst are, however, much higher than with $\mathrm{Pd}-\mathrm{UiO}-66-\mathrm{NH}_{2}$ catalyst. Interestingly, Pd-UiO-66 exhibited high selectivity ( $>90 \%)$ for cyclohexanol, while Pd-UiO-66- $\mathrm{NH}_{2}$ provided $90 \%$ selectivity for cyclohexanone under identical conditions. This difference in activity and selectivity was due to the high hydrogenation efficiency of Pd@UiO66 that converts first phenol to cyclohexanone and, then, further hydrogenation of cyclohexanone to cyclohexanol. On the other hand, the rate of phenol hydrogenation to cyclohexanone by $\mathrm{Pd@UiO-66- \textrm {NH } _ { 2 }}$ was lower enough to stop the reaction at the cyclohexanone step.<smiles>CC(C)CC1CCCCC1</smiles>

Scheme 16. Conversion of phenol to cyclohexanone and cyclohexanol by Pd@UiO-66.

Pd NPs $(1.5-2.5 \mathrm{~nm})$ were encapsulated on UiO-66- $\mathrm{NH}_{2}$ by introducing a palladium precursor in this MOF via a direct anionic exchange and subsequent $\mathrm{H}_{2}$ reduction and its activity was studied in the hydrodeoxygenation of vanillin in water (Scheme 17). ${ }^{[93]}$ A complete conversion of vanillin with exclusive selectivity for 2-methoxy-4-methylphenol was achieved with 2.0 wt\% $\mathrm{Pd} @$ UiO-66- $\mathrm{NH}_{2}$ catalyst at $80{ }^{\circ} \mathrm{C}$ in water. Furthermore, the catalytic activity and selectivity were constant for six reaction cycles indicating excellent stability of this catalyst. The superior performance of $\mathrm{Pd} @ \mathrm{UiO}-66-\mathrm{NH}_{2}$ with respect to other catalysts was attributed to the cooperative effect between uniformly dispersed metallic Pd NPs and the amine-functionalized MOFs providing acid (metal node) and basic $\left(-\mathrm{NH}_{2}\right)$ sites. 


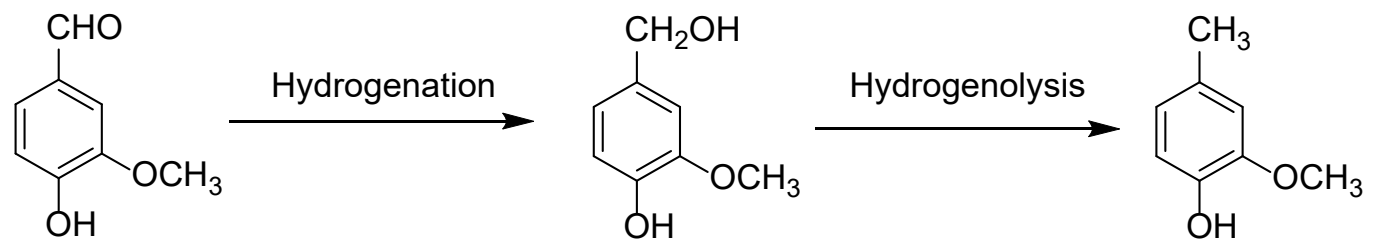

Scheme 17. Possible reaction pathways for the hydrodeoxygenation of vanillin to 2-methoxy4-methylphenol.

Metal NPs loaded within UiO-66 can be served to develop multisite catalysts. In one of these less-abundant examples, Pd was loaded on UiO-66 by impregnation and the particles deposited on sulfonated graphene oxide (Pd@UiO-66/SGO) (SGO stands for sulfonated graphene oxide). The resulting composite was used as heterogeneous catalyst for the one-pot conversion of fructose and glucose into 2,5-dimethylfuran (2,5-DMF) (Scheme 18). ${ }^{[94]}$ The HR-TEM image of Pd@UiO-66/SGO (4.8 \% Pd loading) showed a uniform distribution of Pd NPs with a mean size of $3.5 \pm 0.5 \mathrm{~nm}$ on the particles of UiO-66. This small Pd particle size is compatible with the internal location of these Pd NPs within the pores of the UiO-66 (Figure 15). Under the optimized reaction conditions, Pd@UiO-66/SGO (4.8 \% Pd loading) exhibited $91.8 \%$ conversion of fructose with the selectivity to $2,5-\mathrm{DMF}$ of $70.5 \%$ at $160{ }^{\circ} \mathrm{C}$, under 1 $\mathrm{MPa} \mathrm{H}_{2}$ in tetrahydrofuran. This transformation of fructose into 2,5-DMF requires the combined action of various catalytic sites, namely the Brönsted acidity associated with SGO promotes the fructose dehydration to HMF, while the Pd NPs convert HMF to 2,5-DMF by hydrogenolysis and hydrogenation. One of the main advantages of the direct conversion of fructose into 2,5-DMF is that the process takes place without additional purification of HMF from the reaction mixture. Furthermore, 4.8\% Pd@UiO-66/SGO is also active for glucose conversion reaching a selectivity to $2,5-\mathrm{DMF}$ of $45.3 \%$ at $87.3 \%$ conversion. Recyclability test for fructose conversion showed that 4.8 wt\% Pd@UiO-66/SGO catalyst can be reused five times. However, the 2,5-DMF yield decreased somewhat rapidly from 70.5 to $58.3 \%$ in the second run, although in the subsequent cycles the yield decreased only slightly to $52.1 \%$. The 
decrease in 2,5-DMF yield upon reuse is accompanied by the increase in the HMF yield rapidly from 5.6 to $14.2 \%$ in the second run, and then slowly up to $19.8 \%$ in the fifth run. This variation in the product selectivity indicates that the steps of the tandem process related with acid sites occur more sluggishly in the used Pd/UiO-66@SGO than in the fresh sample.<smiles>O=CC(O)C(O)C(O)CO</smiles><smiles>O=Cc1ccc(CO)o1</smiles>

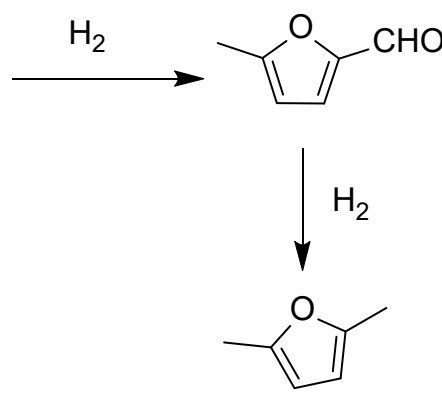

Scheme 18. Conversion of glucose to 2,5-DMF using Pd@UiO-66/SGO.
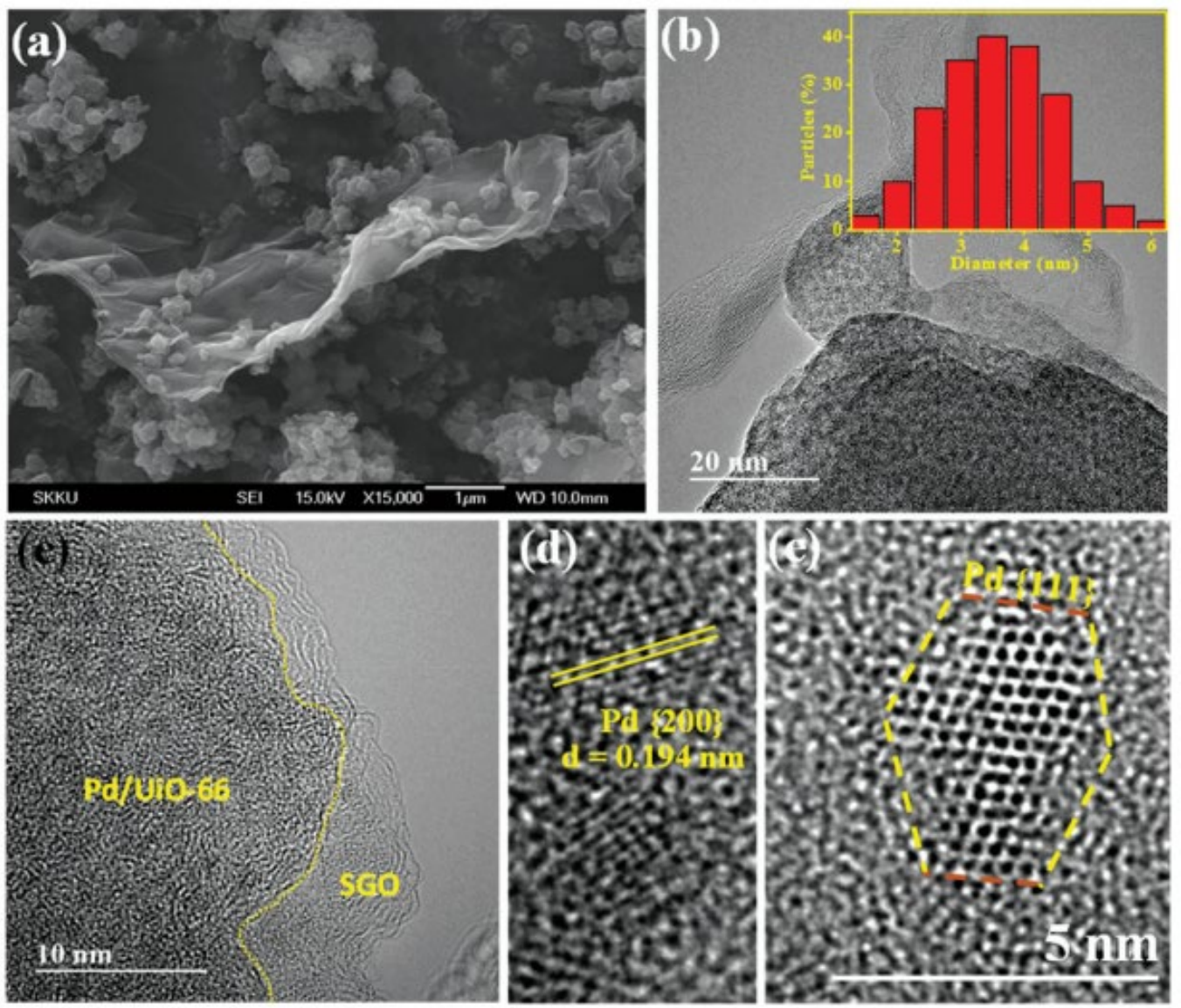

Figure 15. 4.8 Pd@UiO-66/SGO catalyst surface morphology: (a) SEM image and (b-e) the corresponding HR-TEM images. The inset in (b) shows the size distribution of Pd. Panel d 
shows the interlayer distance corresponding to Pd 200 plane. Reproduced with permission from ref.[94]. Copyright 2017 Royal Society of Chemistry.

Cross-coupling reactions have become among the most useful and versatile reactions in modern organic synthesis since they can be applied to a wide range of aryl halides or other arenes substituted by leaving groups using a wide range of reagents, including boronic acids, alkenes, alkynes, phenols, thiols and amines, as well as organometallic reagents, among others. ${ }^{[95,96]}$ The reaction conditions are typically mild, the yields can be high, the scope is broad and the coupling can be compatible with a wide range of other functional groups.

These cross-coupling reactions are typically catalyzed by Pd NPs and, no surprisingly, UiO-66 has been one of the preferred hosts. Thus, Pd NPs were supported on UiO-66- $\mathrm{NH}_{2}$ by a direct anionic exchange followed by chemical reduction by methanol in sodium acetate. The resulting $\mathrm{Pd} @ \mathrm{UiO}-66-\mathrm{NH}_{2}$ was tested as catalyst for the Suzuki-Miyaura cross coupling reaction. ${ }^{[97]}$ It should be noted, however, that the average particle size of Pd NPs was $5.28 \pm 0.5$ nm, too large to be occluded within the internal pores of UiO-66. Pd@UiO-66- $\mathrm{NH}_{2}$ as catalyst afforded $92 \%$ yield (TOF: $2190.5 \mathrm{~h}^{-1}$ ) for the coupling of iodobenzene and phenylboronic acid in $\mathrm{DMF} / \mathrm{H}_{2} \mathrm{O}$ using $\mathrm{K}_{2} \mathrm{CO}_{3}$ as base at $60{ }^{\circ} \mathrm{C}$. Even more importantly, chlorobenzene as a reactant gave $80 \%$ yield (TOF: $467.8 \mathrm{~h}^{-1}$ ) at $80{ }^{\circ} \mathrm{C}$. The catalyst could be reused in five consecutive cycles for the coupling of iodobenzene. Powder XRD patterns indicated that the UiO-66- $\mathrm{NH}_{2}$ structure was not altered after five cycles. Interestingly, Pd@MIL-53(Al)-NH (TOF: $\left.396 \mathrm{~h}^{-1}\right)^{[98]}$ and IRMOF-3-PI-Pd (TOF: $\left.2037 \mathrm{~h}^{-1}\right)^{[99]}$ exhibit lower TOF values than $\mathrm{Pd} @$ UiO-66- $\mathrm{NH}_{2}$. These comparative catalytic data clearly illustrate the role of the MOF, namely, UiO-66- $\mathrm{NH}_{2}$ enhancing the intrinsic catalytic activity of Pd NPs in the Suzuki-Miyaura cross-coupling.

In another example, Pd NPs were incorporated within UiO-66 by dispersing $\mathrm{H}_{2} \mathrm{PdCl}_{4}$ followed by reduction with $\mathrm{NaBH}_{4}$ with microwave. The activity of the resulting $\mathrm{Pd} @ \mathrm{UiO}-66$ 
was examined in Suzuki-Miyaura cross-coupling reaction. Pd@UiO-66 (Pd NPs 5 nm average size) afforded $90 \%$ yield of biphenyl for the coupling of bromobenzene and phenylboronic acid

at $30{ }^{\circ} \mathrm{C}$ using $\mathrm{K}_{2} \mathrm{CO}_{3}$ as base. ${ }^{[100]}$ However, the same reaction with chlorobenzene as substrate required much longer time and afforded only $29 \%$ yield under otherwise identical conditions. The catalyst was recycled for five successive runs with slight decay in the yield. This minor deactivation was attributed to the agglomeration of Pd NPs under the reaction conditions, as evidenced from TEM images. In another precedent, Pd@UiO-66 (average Pd NPs size 8.56 $\mathrm{nm}$ ) promoted the cross-coupling reaction of iodobenzene and phenylboronic acid, achieving complete conversion and selectivity to biphenyl with a TON value of 172 using $\mathrm{K}_{2} \mathrm{CO}_{3}$ as base at $80{ }^{\circ} \mathrm{C} \cdot{ }^{[101]}$ The catalyst can be recycled four times without significant decay in its catalytic activity.

\section{$5.3 \mathrm{Cu}$ NPs}

Due to the affordability and cost, there is much interest in exploiting the catalytic properties of earth-abundant metals, such as $\mathrm{Cu}$, replacing costly noble metals. In this aspect, $\mathrm{Cu}(\mathrm{OAc})_{2}$ was adsorbed on $\mathrm{UiO}-66-\mathrm{NH}_{2}$ nanocrystals in ethanol at room temperature to obtain $\mathrm{Cu}(\mathrm{II}) @$ UiO-66- $\mathrm{NH}_{2}$ which upon reduction with $\mathrm{NaBH}_{4}$ resulted in $\mathrm{Cu} @ U$ UiO-66- $\mathrm{NH}_{2}$. The catalytic activity of $\mathrm{Cu} @ \mathrm{UiO}-66-\mathrm{NH}_{2}$ was examined in the reduction of styrene using hydrazine as reducing agent. ${ }^{[102]}$ HRTEM images revealed the existence of spherical shaped $\mathrm{Cu}$ particles which are uniformly distributed with an average size of 4-6 nm. Cu@UiO-66- $\mathrm{NH}_{2}$ catalyst completely converted styrene to ethylbenzene using hydrazine hydrate at room temperature in ethanol with a TOF value of $100 \mathrm{~h}^{-1}$. The catalyst was reused five times without any decay in conversion and selectivity. However, some $\mathrm{Cu}$ leaching after five catalytic runs of $5.8 \%$ was determined. The crystallinity and MOF structural integrity was retained after the fifth cycle, as confirmed by powder XRD. HRTEM analysis revealed that the mean diameter 
of the $\mathrm{Cu}$ NPs slightly increased after five runs, suggesting that $\mathrm{Cu} @ \mathrm{UiO}-66-\mathrm{NH}_{2}$ would undergo some deactivation upon extended use.

Recently, the activity and selectivity of $\mathrm{Cu}$ NPs obtained by the polyol method in the $\mathrm{CO}_{2}$ hydrogenation to methanol was altered by surrounding large individual $\mathrm{Cu}$ NPs cores (18 $\mathrm{nm})$ with a dense shell of UiO-66 (CucUiO-66) using polyvinylpyrrolidone as interface. ${ }^{[103]}$ Catalytic hydrogenation of $\mathrm{CO}_{2}$ to methanol could be one of the key reactions in a possible scenario of low $\mathrm{CO}_{2}$ emissions. Using renewable energy to obtain hydrogen from water, $\mathrm{CO}_{2}$ hydrogenation can serve for the preparation of liquid chemicals that can be used as fuels or as precursors of a large diversity of bulk chemicals and commodities. ${ }^{[104-106]}$ It was proposed that in $\mathrm{Cu} \subset \mathrm{UiO}-66$ there is a strong interaction between the single $\mathrm{Cu} \mathrm{NP}$ at the core and the $\mathrm{Zr}_{6}(\mathrm{OH})_{4} \mathrm{O}_{4}$ building units. In contrast, $\mathrm{Cu}$ NPs immobilized on UiO-66 (denoted as " $\mathrm{Cu}$ on UiO-66") was synthesised by depositing Cu NPs on the pre-synthesized UiO-66 by mixing colloidal solutions of $\mathrm{Cu}$ NCs and UiO-66. ICP-AES measurements showed 1 and $1.4 \mathrm{wt} \%$ of $\mathrm{Cu}$ in $\mathrm{Cu} \subset \mathrm{UiO}-66$ and $\mathrm{Cu}$ on UiO-66 samples, respectively. Figure 16 compares the TEM images of $\mathrm{Cu} \subset \mathrm{UiO}-66$ and $\mathrm{Cu}$ on UiO-66 catalysts showing the remarkable differences between the two samples arising from the different preparation methods. The catalytic performance of CucUiO-66 exhibited 8-fold enhancement in the activity with $100 \%$ selectivity to methanol compared to the benchmark $\mathrm{Cu} / \mathrm{ZnO} / \mathrm{Al}_{2} \mathrm{O}_{3}$ catalyst. ${ }^{[107]}$ The initial TOF values achieved by $\mathrm{Cu}$ on $\mathrm{UiO}-66, \mathrm{Cu}$ on $\mathrm{ZrO}$, and $\mathrm{Cu} / \mathrm{ZnO} / \mathrm{Al}_{2} \mathrm{O}_{3}$ for the methanol formation under the same conditions were $3.7 \times 10^{-3}, 1.7 \times 10^{-3}, 0.42 \times 10^{-3}$ and $0.45 \times 10^{-3} \mathrm{~s}^{-1}$, respectively. On the other hand, $\mathrm{Cu}$ NPs on MIL-101(Cr) and Cu NPs $\subset$ ZIF-8 showed no catalytic activity. Interestingly, XPS data showed that the $\mathrm{Zr} 3 \mathrm{~d}$ binding energy of these ions on surface of the catalyst is shifted toward lower oxidation state in the presence of $\mathrm{Cu}$ NP. This shift in the XPS binding energy of $\mathrm{Zr} 3 \mathrm{~d}$ is the main spectroscopic evidence supporting a strong interaction 
between $\mathrm{Cu} \mathrm{NP}$ and $\mathrm{Zr}^{4+}$ at the nodes of the MOF and this interaction is proposed to be one of the main reasons for the high activity of $\mathrm{Cu}$ NPs $\subset$ UiO-66 catalyst.
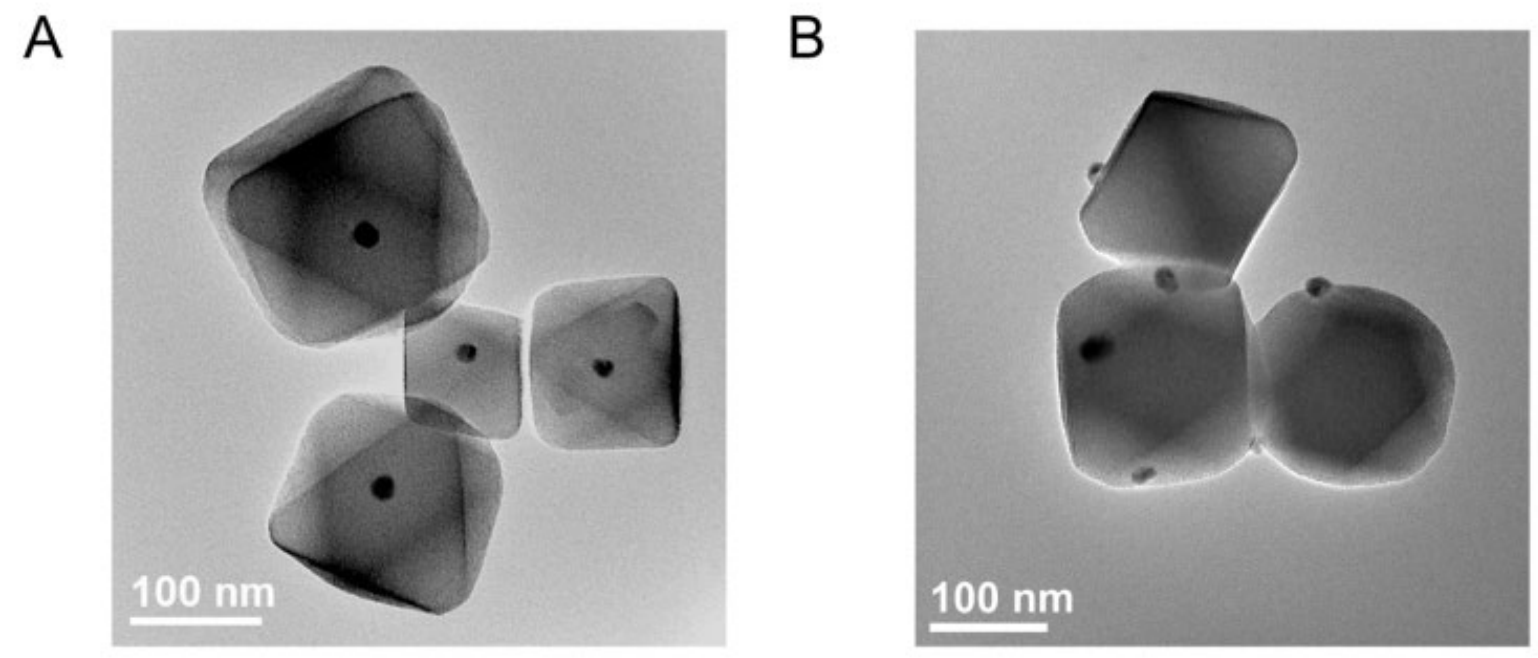

Figure 16. TEM images of (A) CucUiO-66 (single $\mathrm{Cu}$ NP inside UiO-66) and (B) $\mathrm{Cu}$ on UiO66. Reproduced with permission from ref [103]. Copyright 2016 American Chemical Society.

\subsection{Other metal NPs}

$\mathrm{Au}$ NPs were homogeneously synthesised in-situ on UiO-66 host matrix to afford $\mathrm{Au} @$ UiO-66 and its catalytic activity was examined in the aerobic oxidation of benzyl alcohol. ${ }^{[108]}$ The average Au NP size in Au@UiO-66 was 7 nm that is somewhat larger than the dimensions of the UiO-66 cavities $(<2 \mathrm{~nm})$, indicating that either these Au NPs are located in defects, or cause a distortion of the lattice or, more probably, are located on the external surface of the crystallites. Au@UiO-66 exhibited 94 \% conversion of benzyl alcohol with 100 $\%$ selectivity to benzaldehyde when the reaction is carried out in toluene at $100{ }^{\circ} \mathrm{C}$ in the absence of base. Under identical conditions, the conversion of benzyl alcohol reached $83 \%$ conversion with $100 \%$ selectivity of benzaldehyde using air as oxidant. Reusability and stability tests showed the $\mathrm{Au} @ \mathrm{UiO}-66$ catalyst can be recycled in two consecutive runs with a negligible leaching of Au species and no loss of crystallinity of the UiO-66 host as indicated by powder XRD. 
Although $\mathrm{NH}_{2}$ groups are the substituents most widely used to interact with embedded metal NPs, other substituents on the aromatic ring of the BDC linker can also establish interactions with the metal NPs guests. A dual functional catalyst, namely, Ru NPs deposited by wet impregnation method on sulfonic acid-functionalized UiO-66 $\left(\mathrm{Ru} / \mathrm{UiO}-66-\mathrm{SO}_{3} \mathrm{H}\right)$ was prepared and its activity was evaluated in the conversion of methyl levulinate into GVL (Scheme 19). ${ }^{[109]}$ Acid-base titrations indicated that the acidity of $\mathrm{Ru} / \mathrm{UiO}-66-\mathrm{SO}_{3} \mathrm{H}$ was 0.35 mmol $\mathrm{g}^{-1}$. TEM images confirmed the uniform distribution of $\mathrm{Ru} \mathrm{NPs}$ on $\mathrm{UiO}-66-\mathrm{SO}_{3} \mathrm{H}$ matrix with the size ranging between $2-4 \mathrm{~nm}$. This size range of Ru NPs is compatible with the internal location of the $\mathrm{Ru}$ NPs inside the UiO-66 pore. A $5 \mathrm{wt} \% \mathrm{Ru} / \mathrm{UiO}-66-\mathrm{SO}_{3} \mathrm{H}$ catalyst resulted in quantitative conversion of methyl levulinate with a selectivity of GVL to $74.5 \%$ at $70{ }^{\circ} \mathrm{C}$ under $0.5 \mathrm{MPa} \mathrm{H}_{2}$ in water. The catalytic activity and selectivity of $\mathrm{Ru} / \mathrm{UiO}-66-\mathrm{SO}_{3} \mathrm{H}$ was considerably reduced upon neutralization of its acidic sites by the purposely addition of $\mathrm{NaOH}$, thereby confirming the important role of the sulfonic acid groups in promoting the intramolecular dehydroxylation of the 4-hydroxypentanoic acid methyl ester (4-HPME) intermediate (Figure 17). Also, the $\mathrm{Ru} / \mathrm{UiO}-66-\mathrm{SO}_{3} \mathrm{H}$ catalyst was recyclable over five cycles without any significant decay in its catalytic activity.

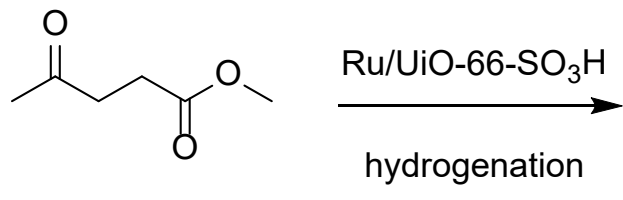

methyl levulinate<smiles>COC(=O)CCC(C)O</smiles>

4-HPME

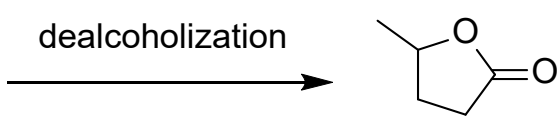

GVL

Scheme 19. Conversion of methyl levulinate to GVL catalyzed by $\mathrm{Ru} / \mathrm{UiO}-66-\mathrm{SO}_{3} \mathrm{H}$. 


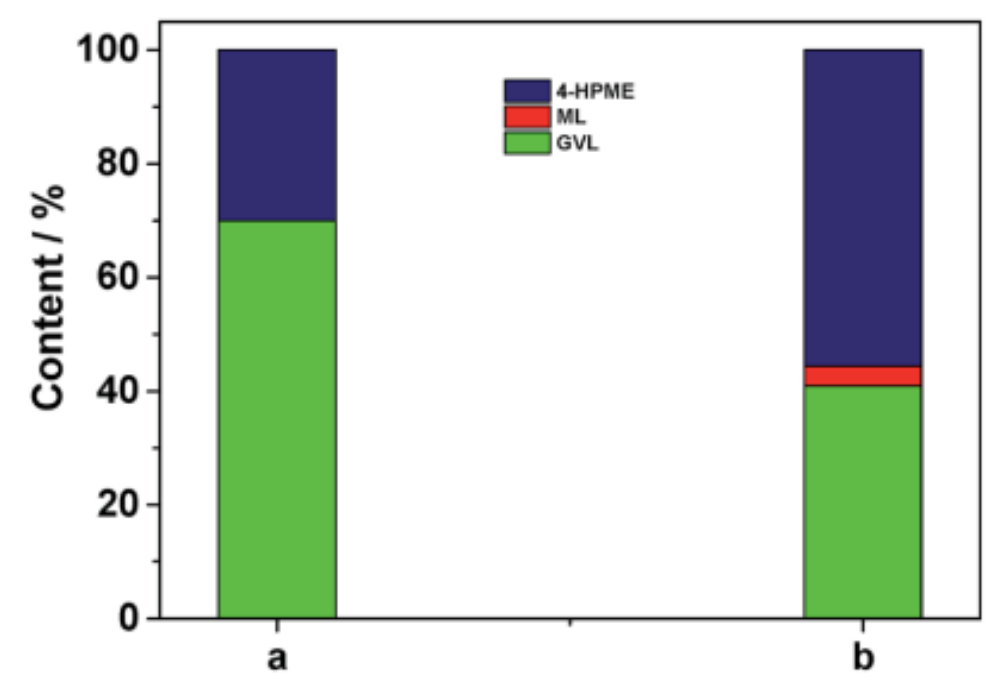

Figure 17. Activity data for the cascade catalytic hydrogenation-cyclization of methyl levulinate over $5.0 \mathrm{wt} \% \mathrm{Ru} / \mathrm{SO}_{3} \mathrm{H}-\mathrm{UiO}-66$ in (a) the absence and (b) the presence of $0.02 \mathrm{mmol}$ $\mathrm{NaOH}$. Reproduced with permission from ref [109]. Copyright 2017 Royal Society of Chemistry.

Bimetallic NPs have also been incorporated inside UiO-66. Bimetallic NPs, either as nano alloys or structured as core-shell particles can exhibit unique catalytic properties respect to the behaviour of the individual counterparts, because the electron density at one metal atom is different from that of the pure metal and can be altered by the proportion of the second metal. To minimize growth and agglomeration of these bimetallic NPs, confinement inside the pores of MOFs is, again, an appealing possibility. In one of the few examples of bimetallic NPs with UiO-66, Ag and Pd nanoalloy was encapsulated within UiO-66- $\mathrm{NH}_{2}\left(\mathrm{AgPd} @ \mathrm{UiO}-66-\mathrm{NH}_{2}\right)$ by in-situ co-reduction method and its activity was tested in the hydrolysis of ammonia borane. ${ }^{[110]}$ Among the series of catalysts screened for this reaction, the $\mathrm{Ag}_{1} \mathrm{Pd}_{4} @ \mathrm{UiO}-66-\mathrm{NH}_{2}$ exhibited the highest catalytic activity for the hydrolysis of ammonia borane with a TOF value of $90 \mathrm{~mol}$ $\mathrm{H}_{2}$ mol catalyst ${ }^{-1} \mathrm{~min}^{-1}$. The activity of $\mathrm{Ag}_{1} \mathrm{Pd}_{4} @ \mathrm{UiO}-66-\mathrm{NH}_{2}$ was mostly retained after three runs, but, however, a significant loss of activity after being used repetitively for five times was 
observed. This catalytic deactivation was believed to be due to the agglomeration of AgPd NPs on the external surfaces of MOFs.

In another example, the catalytic activity of encapsulated alloy PdPt@UiO-66 was tested in the size selective hydrogenation of nitrobenzene to aniline, observing that the activity of encapsulated PdPt nanoalloys were much superior $\left(790 \mathrm{~h}^{-1}\right)$ to the value observed for Pt@UiO-66 $\left(322 \mathrm{~h}^{-1}\right)$ under identical reaction conditions. ${ }^{[111]}$ This enhanced activity of the former catalyst is believed to be due to synergistic effect of the two metals in the alloy.

A synergistic catalysis of plasmonic core $(\mathrm{Au}) / \mathrm{shell}(\mathrm{Pd}), \mathrm{Au} @ \mathrm{Pd}$ NPs supported on titanium-doped zirconium-based amine functionalized MOFs (UiO-66- $\mathrm{NH}_{2}\left(\mathrm{Zr}_{85} \mathrm{Ti}_{15}\right)$ was reported for the visible light assisted room-temperature hydrogen production from formic acid. ${ }^{[12]}$ TEM images of $\mathrm{Au} @ \mathrm{Pd} / \mathrm{UiO}-66\left(\mathrm{Zr}_{85} \mathrm{Ti}_{15}\right)$ showed the mean size of $\mathrm{Au} @ \mathrm{Pd}$ to be of $7.3 \mathrm{~nm}$ on MOF without significant agglomeration. These dimensions of $\mathrm{Au} @ \mathrm{Pd}$ are, however, larger than the dimensions of UiO-66- $\mathrm{NH}_{2}$ cavities. The experimental results revealed that $\mathrm{Pd}$ atoms become electronically promoted when the Au core absorbs one photon at the localized surface plasmon band. On the other hand, the amine groups at the linker and titanium ion dopants at the nodes play crucial roles in achieving an exceptional catalytic performance (Figure 18). For instance, $\mathrm{Au} @ \mathrm{Pd} / \mathrm{UiO}-66-\mathrm{NH}_{2}\left(\mathrm{Zr}_{85} \mathrm{Ti}_{15}\right)$ reached a high hydrogen production rate of $42000 \mathrm{~mL} \mathrm{~h}^{-1} \mathrm{~g}^{-1}$ (based on Pd) with high TOF value of $200 \mathrm{~h}^{-1}$ upon visible light irradiation at $30{ }^{\circ} \mathrm{C}$. This activity was much higher compared to $\mathrm{Au} @ \mathrm{Pd} / \mathrm{N}-\mathrm{rGO}\left(89 \mathrm{~h}^{-1}, 25^{\circ} \mathrm{C}\right)$ [N-rGO: nitrogen doped reduced graphene oxide ${ }^{[113]} \mathrm{Ag} @$ Pd core-shell nanocatalyst (156 h 1, $\left.35{ }^{\circ} \mathrm{C}\right),{ }^{[14]} \mathrm{Pd} / \mathrm{H}-\operatorname{BETA}\left(59.2 \mathrm{~h}^{-1}, 50{ }^{\circ} \mathrm{C}\right),{ }^{[115]}$ and Au@Pd/ED-MIL-101 (ED: ethylene diamine) $\left(106 \mathrm{~h}^{-1}, 90{ }^{\circ} \mathrm{C}\right) .{ }^{[16]}$ In addition, the $\mathrm{Au} @ \mathrm{Pd} / \mathrm{UiO}-66\left(\mathrm{Zr}_{85} \mathrm{Ti}_{15}\right)$ exhibited considerable stability and it was recycled three times with a slight decrease in activity for the hydrogen production. This minor activity decrease was due to partial deterioration of the crystallinity during the reaction. 


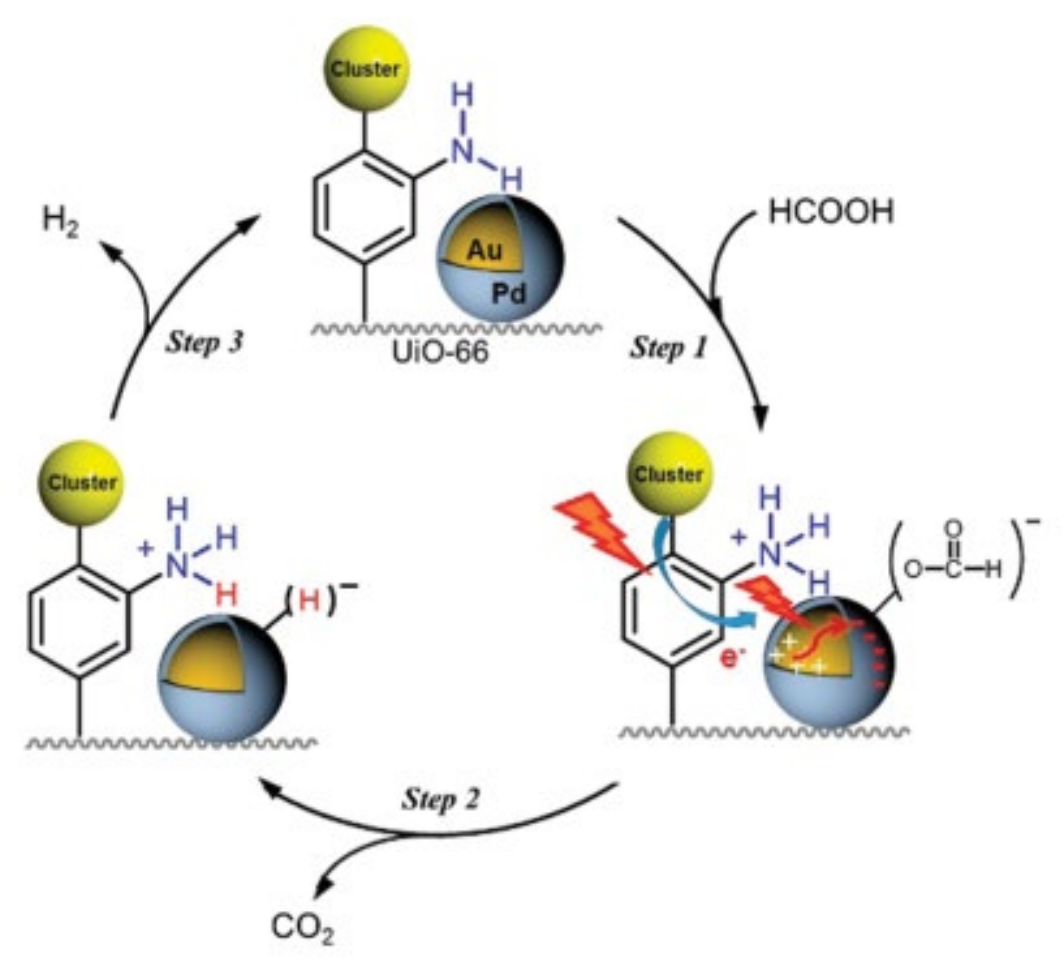

Figure 18. Possible reaction pathway for visible light enhanced hydrogen production from formic acid decomposition by $\mathrm{Au} @ \mathrm{Pd} / \mathrm{UiO}-66\left(\mathrm{Zr}_{85} \mathrm{Ti}_{15}\right)$. Reproduced with permission from ref [112]. Copyright 2017 American Chemical Society.

The reader is also referred to the existing literature for UiO-66 based photocatalytic reactions $^{[117-119]}$ as this topic is out of the objectives of the present review.

There are other articles reported in the existing literature for the incorporation of metal NPs within the pores of UiO-66, having or not substituents at the BDC linker that have been used as heterogeneous catalysts. For example, transfer hydrogenation of nitrobenzene to aniline in water using $\mathrm{Pd} @$ UiO-66- $\mathrm{NH}_{2},{ }^{[120]}$ one-pot tandem reaction involving selective oxidation of primary alcohols followed by Knoevenagel condensation reaction using $\mathrm{Au} @ \mathrm{UiO}-66-\mathrm{NH}_{2},{ }^{[121]}$ liquid phase hydrogenation of furfural to furfuryl alcohol with $\mathrm{Ru} @ \mathrm{UiO}-66^{[122]}$ and dehydrogenation of formic acid at room temperature using Ag-Pd alloy@UiO-66- $\mathrm{NH}_{2}$ as catalyst $^{[123]}$ among many other examples. ${ }^{[124]}$ 
Besides metal NPs, metal oxide NPs also exhibit remarkable catalytic activity and can similarly be stabilized against sintering by adsorption/incorporation within the pores of UiO66. The UiO-66- $\mathrm{NH}_{2}$ was modified with melamine via a post-synthetic approach consisting in the reaction of cyanuric chloride with the $\mathrm{NH}_{2}$ groups of the amino-BDC linker and final substitution of the chloride leaving groups by amino ones (Figure 19). The melamine modified UiO-66- $\mathrm{NH}_{2}$ (UiO-66- $\left.\mathrm{NH}_{2}-\mathrm{MIm}\right)$ (MIm: melamine) was employed to load $\mathrm{CuO}$ NPs through interaction with the amine groups and $\pi$-electron stacking with melamine as shown in Figure 19. ${ }^{[125]}$ The particle size of $\mathrm{CuO}$ was $10-20 \mathrm{~nm}$ that is too large to consider that they can be incorporated inside the pores of the perfect UiO-66 lattice. The activity of the as-synthesised UiO-66- $\mathrm{NH}_{2}-\mathrm{MIm} / \mathrm{CuO}$ was tested in the $\mathrm{C}-\mathrm{O}$ coupling reaction between bromobenzene and phenol. Under the optimized reaction conditions, $93 \%$ yield of diphenyl ether was achieved using UiO-66- $\mathrm{NH}_{2}-\mathrm{MIm} / \mathrm{CuO}$ as catalyst in $\mathrm{DMSO}$ and $\mathrm{KOH}$ as base at $110{ }^{\circ} \mathrm{C}$. A series of substituted diphenyl ethers were synthesised using this catalytic system with yields in the range between 65 to $95 \%$. However, the yield of diphenyl ether was significantly reduced to $30 \%$ when chlorobenzene was used as reagent instead of bromobenzene under identical conditions. Interestingly, the $\mathrm{UiO}-66-\mathrm{NH}_{2}-\mathrm{Mlm} / \mathrm{CuO}$ catalyst showed minor deactivation after five consecutive reactions and this deactivation was attributed to the partial blockage of the pores. On the other hand, powder XRD indicated that the structure and composition of UiO-66- $\mathrm{NH}_{2}-$ $\mathrm{Mlm} / \mathrm{CuO}$ was retained during recycling experiments. 

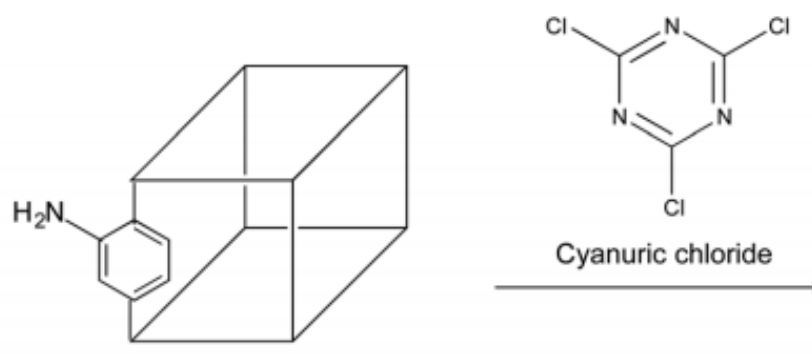

UiO-66- $\mathrm{NH}_{2}$

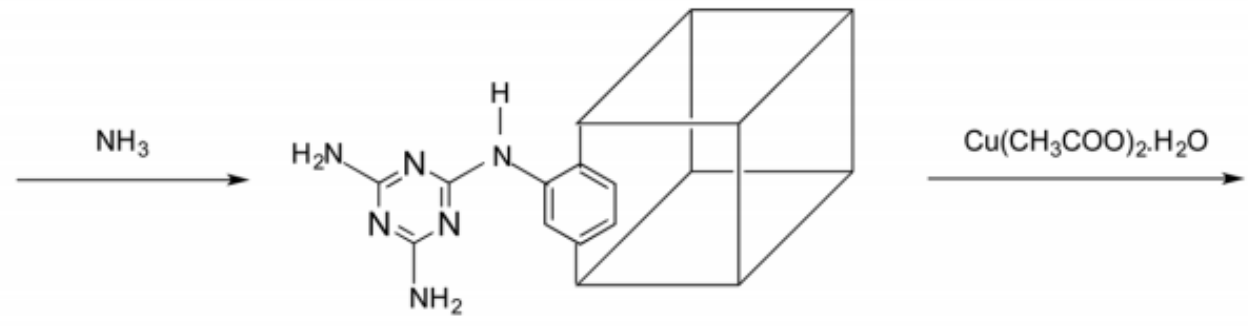

UiO-66- $\mathrm{NH}_{2}-\mathrm{Mlm}$

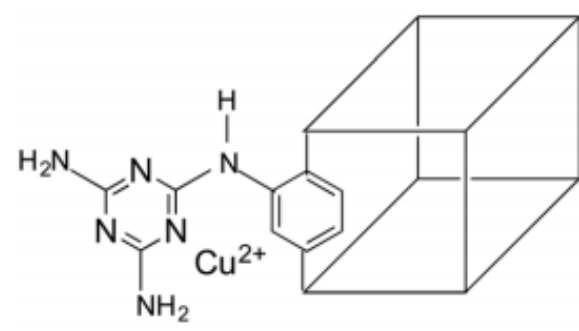

UiO-66- $\mathrm{NH}_{2}-\mathrm{Mlm} / \mathrm{Cu}^{2+}$

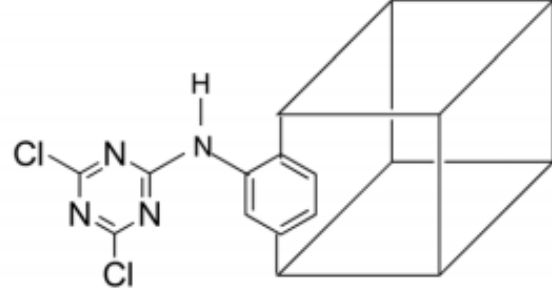

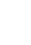


1 (shell thickness $<50 \mathrm{~nm}$ ) and $\mathrm{Fe}_{3} \mathrm{O}_{4} @$ UiO-66- $\mathrm{NH}_{2}-3$ (shell thickness 150-200 nm) were 28.9 $\mathrm{h}^{-1}$ and $24.4 \mathrm{~h}^{-1}$, respectively, under identical reaction conditions. The yields and selectivities were identical in four consecutive runs using $\mathrm{Fe}_{3} \mathrm{O}_{4} @ \mathrm{UiO}-66-\mathrm{NH}_{2}-3$ as catalyst.

Besides metal and metal oxide NPs, UiO-66 can also be used as host for other different types of inorganic or organic guests that can act as catalytic sites. In one of these examples, heteropoly acids, such as phosphotungstic acid (HPW), have been incorporated within MOFs. Heteropoly acids are strong Brönsted acids, but they are also redox catalysts and photocatalysts. $^{[127]}$ These catalytic properties inherent to HPW are also present when these molecular compounds are incorporated inside the pores of MOFs, particularly UiO-66. In one of these examples, different loadings of HPWs were encapsulated over UiO-66 to obtain HPWs@UiO-66 and their catalytic performance was examined in the oxidation of cyclopentene to glutaraldehyde using hydrogen peroxide as oxidant (Scheme 20). ${ }^{[128]}$ Among the various catalysts screened for this oxidation reaction, 35 wt \% HPWs@UiO-66 catalyst exhibited $94.8 \%$ conversion of cyclopentene with glutaraldehyde yield of $78.3 \%$ at $35{ }^{\circ} \mathrm{C}$. Furthermore, the catalyst showed no deactivation for three reaction cycles. This activity was attributed to the cooperation of the redox activity of HPW with the presence of additional Lewis acid sites as evidenced by $\mathrm{CO}$ adsorption experiments monitored by FT-IR spectroscopy that shows characteristic wavenumbers for $\mathrm{CO}$ adsorbed on this type of site.

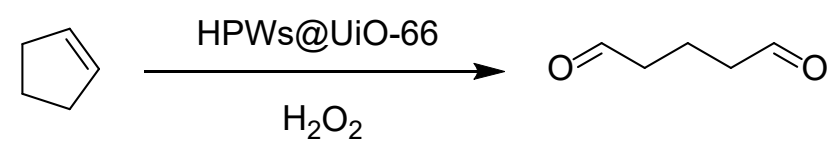

Scheme 20. Oxidation of cyclopentene to glutaraldehyde catalyzed by 35 wt \% HPWs@UiO66.

\section{Conclusions and future prospects}


This review has illustrated the various possibilities that UiO-66 offers as platform in heterogeneous catalysis based on a large number of studies that have shown the superior performance of this material respect to analogous MOFs or other different supports. It has been shown that this superiority derives from the high structural and chemical stability derive from the presence of highly positive $\mathrm{Zr}^{4+}$ ions, the large porosity and reliable preparation procedures that more recently have allowed the preparation of defective materials with controllable density of defects. Regarding the catalysis, emphasis has been made showing the cases in where a synergy between different types of sites, either Brönsted and Lewis acid sites or acid and basic sites, have been claimed to explain the remarkable activity observed in comparison to other catalysts for some reactions.

It is clear that the current state of the art allows to foresee that the control in the synthesis and postsynthetic modification of UiO-66 will allow a precise tuning of the nodal composition, substitution of the linker and density of defects in such a way that all these parameters will be selected as a function of the reaction mechanism and the wanted catalytic properties. In this way, optimal performance will be achieved for each specific set of substrates and reactions. Furthermore, more examples on the development of tandem and cascade reactions by using UiO-66 with two or more different independent sites in the same UiO-66 will appear, showing the potential that UiO-66 offer in this regard. The final goal in this area is to implement a commercial process based on the use of UiO-66 as catalysts, because in this way it will be convincingly show the advantages of this material respect to other alternative catalysts.

\section{Acknowledgements}

AD thanks the University Grants Commission, New Delhi, for the award of an Assistant Professorship under its Faculty Recharge Programme. AD also thanks the Department of 
Science and Technology, India, for the financial support through Extra Mural Research

Funding (EMR/2016/006500). Financial support by the Spanish Ministry of Economy and Competitiveness (Severo Ochoa and CTQ2015-69153-CO2-1) and Generalitat Valenciana (Prometeo 2017-083) is gratefully acknowledged.

Keywords: Heterogeneous Catalysis; UiO-66; UiO-67; Active Sites; Engineering MOFs; Sustainable Chemistry.

\section{References}

[1] Z. Qiu, S. Ren and Z. Xie, Acc. Chem. Res. 2011 44, 299-309.

[2] B. F. Hoskins and R. Robson, J. Am. Chem. Soc. 1989, 111, 5962-5964.

[3] C. D. Wu and W. Lin, Angew. Chem., Int. Ed. 2007, 46, 1075-1078.

[4] A. Corma, H. Garcia and F. X. Llabres i Xamena, Chem. Rev. 2010, 110, 4606-4655.

[5] Z. Wang, G. Chen and K. Ding, Chem. Rev. 2009, 109, 322-359.

[6] H. Furukawa, K. E. Cordova, M. O'Keeffe and O. M. Yaghi, Science 2013, 341, 1230444.

[7] H.-C. Zhou, J. R. Long and O. M. Yaghi, Chem. Rev. 2012, 112, 673-674.

[8] J. Liang, Z. Liang, R. Zou and Y. Zhao, Adv. Mater. 2017, 29, 1701139

[9] J. H. Cavka, S. Jakobsen, U. Olsbye, N. Guillou, C. Lamberti, S. Bordiga and K. P. Lillerud, J. Am. Chem. Soc. 2008, 130, 13850-13851.

[10] M. Kandiah, M. H. Nilsen, S. Usseglio, S. Jakobsen, U. Olsbye, M. Tilset, C. Larabi, E. A. Quadrelli, F. Bonino and K. P. Lillerud, Chem. Mater. 2010, 22, 6632-6640.

[11] V. V. Butova, M. A. Soldatov, A. A. Guda, K. A. Lomachenko and C. Lamberti, Russ. Chem. Rev. 2016, 85 280-307.

[12] A. Schaate, P. Roy, A. Godt, J. Lippke, F. Waltz, M. Wiebcke and P. Behrens, Chem. Eur. J. 2011, $17,6643-6651$.

[13] G. C. Shearer, S. Chavan, J. Ethiraj, J. G. Vitillo, S. Svelle, U. Olsbye, C. Lamberti, S. Bordiga and K. P. Lillerud, Chem. Mater. 2014, 26, 4068-4071.

[14] H. Wu, Y. S. Chua, V. Krungleviciute, M. Tyagi, P. Chen, T. Yildirim and W. Zhou, J. Am. Chem. Soc. 2013, 135 10525-10532.

[15] G. C. Shearer, S. Chavan, S. Bordiga, S. Svelle, U. Olsbye and K. P. Lillerud, Chem. Mater. 2016, 28 3749-3761.

[16] A. De Vos, K. Hendrickx, P. Van Der Voort, V. V. Speybroeck and K. Lejaeghere, Chem. Mater. 2017, 29 3006-3019.

[17] M. Taddei, Coord. Chem. Rev. 2017, 343 1-24.

[18] Z. Hu and D. Zhao, Dalton Trans. 2015, 44, 19018-19040.

[19] Y. Bai, Y. Dou, L.-H. Xie, W. Rutledge, J.-R. Li and H.-C. Zhou, Chem. Soc. Rev. 2016, 45, 2327-2367.

[20] M. Rimoldi, A. J. Howarth, M. R. DeStefano, L. Lin, S. Goswami, P. Li, J. T. Hupp and O. K. Farha, ACS Catal. 2017, 7, 997-1014.

[21] M. Kim and S. M. Cohen, CrystEngComm 2012, 14, 4096-4104.

[22] R. J. Marshall and R. S. Forgan, Eur. J. Inorg. Chem. 2016, 4310-4331.

[23] S. M. Chavan, G. C. Shearer, S. Svelle, U. Olsbye, F. Bonino, J. Ethiraj, K. P. Lillerud and S. Bordiga, Inorg. Chem. 2014, 53 9509-9515.

[24] M. Vandichel, J. Hajek, F. Vermoortele, M. Waroquier, D. E. De Vos and V. Van Speybroeck, CrystEngComm 2015, 17, 395-406. 
[25] F. Vermoortele, B. Bueken, G. Le Bars, B. Van de Voorde, M. Vandichel, K. Houthoofd, A. Vimont, M. Daturi, M. Waroquier, V. V. Speybroeck, C. Kirschhock and D. De Vos, J. Am. Chem. Soc. 2013, 135, 11465-11468.

[26] F.-G. Xi, Y. Yang, H. Liu, H.-F. Yao and E.-Q. Gao, RSC Adv. 2015, 5, 79216-79223.

[27] C. Caratelli, J. Hajek, F. G. Cirujano, M. Waroquier, F. X. Llabrés i Xamena and V. V. Speybroeck, J. Catal. 2017, 352 401-414.

[28] J. Hajek, B. Bueken, M. Waroquier, D. De Vos and V. V. Speybroeck, ChemCatChem 2017, 9, 22032210.

[29] S. Ling and B. Slater, Chem. Sci. 2016, 7, 4706-4712.

[30] U. S. F. Arrozi, H. W. Wijaya, A. Patah and Y. Permana, Appl. Catal. A: Gen. 2015, 506 77-84.

[31] F. G. Cirujano, A. Corma and F. X. Llabrés i Xamena, Catal. Today 2015, 257, 213-220.

[32] S. N. Kim, Y.-R. Lee, S.-H. Hong, M.-S. Jang and W.-S. Ahn, Catal. Today 2015, 245, 54-60.

[33] J. Kim, S.-N. Kim, H.-G. Jang, G. Seo and W.-S. Ahn, Appl. Catal. A: Gen. 2013, 453 175-180.

[34] A. Shaabani, R. Mohammadian, S. E. Hooshmand, A. Hashemzadeh and M. M. Amini, ChemistrySelect 2017, 2, 11906-11911.

[35] V. L. Rechac, F. G. Cirujano, A. Corma and F. X. Llabrés i Xamena, Eur. J. Inorg. Chem. 2016, 45124516.

[36] F. Nouar, M. I. Breeze, B. C. Campo, A. Vimont, G. Clet, M. Daturi, T. Devic, R. Walton and C. Serre, Chem. Commun. 2015, 51, 14458-14461.

[37] C. M. Granadeiro, S. O. Ribeiro, M. Karmaoui, R. Valença, J. C. Ribeiro, B. de Castro, L. Cunha-Silva and S. S. Balula, Chem. Commun. 2015, 51, 13818-13821.

[38] A. H. Valekar, K.-H. Cho, S. K. Chitale, D.-Y. Hong, G.-Y. Cha, U.-H. Lee, D. W. Hwang, C. Serre, J.-S. Chang and Y. K. Hwang, Green Chem. 2016, 18, 4542-4552.

[39] E. Plessers, D. De Vos and M. B. J. Roeffaers, J. Catal. 2016, 340, 136-143.

[40] D. Yang, S. O. Odoh, T. C. Wang, O. K. Farha, J. T. Hupp, C. J. Cramer, L. Gagliardi and B. C. Gates, J. Am. Chem. Soc. 2015, 137, 7391-7396.

[41] H. G. T. Nguyen, N. M. Schweitzer, C.-Y. Chang, T. L. Drake, M. C. So, P. C. Stair, O. K. Farha, J. T. Hupp and S. T. Nguyen, ACS Catal. 2014, 4, 2496-2500.

[42] M. Lammert, M. T. Wharmby, S. Smolders, B. Bueken, A. Lieb, K. A. Lomachenko, D. De Vos and N. Stock, Chem. Commun. 2015, 51, 12578-12581.

[43] R. Dalapati, B. Sakthivel, M. K. Ghosalya, A. Dhakshinamoorthy and S. Biswas, CrystEngComm 2017, 19, 5915-5925.

[44] R. Dalapati, B. Sakthivel, A. Dhakshinamoorthy, A. Buragohain, A. Bhunia, C. Janiak and S. Biswas, CrystEngComm, , 2016, 18, 7855-7864.

[45] H. G. T. Nguyen, L. Mao, A. W. Peters, C. O. Audu, Z. J. Brown, O. K. Farha, J. T. Hupp and S. T. Nguyen, Catal. Sci. Technol. 2015, 5, 4444-4451.

[46] A. Corma, S. Iborra and A. Velty, Chem. Rev. 2007, 107 2411-2502.

[47] D. Zhao, P. Prinsen, Y. Wang, W. Ouyang, F. Delbecq, C. Len and R. Luque, ACS Sustainable Chem. Eng. 2018, 6, 6901-6909.

[48] R. Oozeerally, D. Burnett, T. W. Chamberlain, R. I. Walton and V. Degirmenci, ChemCatChem 2018, 10, 706-709.

[49] G. L. Woolery, G. H. Kuehl, H. C. Timken, A. W. Chester and J. C. Vartuli, Zeolites 1997, 19, 288296.

[50] Z. Wang, L. Wang, Y. Jiang, M. Hunger and J. Huang, ACS Catal. 2014, 4, 1144-1147.

[51] M. Moliner, Y. Roman-Leshkov and M. E. Davis, Proc. Natl. Acad. Sci. USA 2010, 107, 6164 - 6168.

[52] J. Chen, K. Li, L. Chen, R. Liu, X. Huanga and D. Ye, Green Chem. 2014, 16, 2490-2499.

[53] Z. Zhang, ChemSusChem 2016, 9, 156 -171.

[54] R. S. Assary, L. A. Curtiss and J. A. Dumesic, ACS Catal. 2013, 3, 2694-2704.

[55] Y. Kuwahara, W. Kaburagi and T. Fujitani, RSC Adv. 2014, 4, 45848-45855.

[56] Y. Kuwahara, H. Kango and H. Yamashita, ACS Sustain. Chem. Eng. 2017, 5, 1141-1152.

[57] Z. Miao, C. Qi, A. M. Wensley and Y. Luan, RSC Adv. 2016, 6, 67226-67231. 
[58] Y. Luan, N. Zheng, Y. Qi, J. Yu and G. Wang, Eur. J. Inorg. Chem. 2014, 4268-4272.

[59] R. Ghorbani-Vaghei, D. Azarifar, S. Daliran and A. R. Oveisi, RSC Adv. 2016, 6, 29182-29189.

[60] Y.-M. Chung, H.-Y. Kim and W.-S. Ahn, Catal. Lett. 2014, 144, 817-824.

[61] F. G. Cirujano, A. Corma and F. X. Llabrés i Xamena, Chem. Eng. Science 2015, 124 52-60.

[62] K. C. Maheria, J. Kozinski and A. Dalai, Catal. Lett. 2013, 143, 1220-1225.

[63] M. J. Climent, A. Corma, R. Guil-Lopez, S. Iborra and J. Primo, J. Catal. 1998, 175, 70-79.

[64] F. Vermoortele, R. Ameloot, A. Vimont, C. Serre and D. De Vos, Chem. Commun. 2011, $471521-$ 1523.

[65] Y. Yang, H.-F. Yao, F.-G. Xi and E.-Q. Gao, J. Mol. Catal. A: Chem. 2014, 390 198-205.

[66] J. Hajek, M. Vandichel, B. Van de Voorde, B. Bueken, D. De Vos, M. Waroquier and V. V. Speybroeck, J. Catal. 2015, 331 1-12.

[67] Y. Luan, Y. Qi, H. Gao, R. S. Andriamitantsoa, N. Zheng and G. Wang, J. Mater. Chem. A 2015, 3, 17320-17331.

[68] J. Ye and J. K. Johnson, ACS Catal. 2015, 5, 6219-6229.

[69] M. N. Timofeeva, V. N. Panchenko, J. W. Jun, Z. Hasan, M. M. Matrosova and S. H. Jhung, Appl. Catal. A: Gen. 2014, 471 91-97.

[70] M. W. Logan, Y. A. Lau, Y. Zheng, E. A. Hall, M. A. Hettinger, R. P. Marks, M. L. Hosler, F. M. Rossi, Y. Yuan and F. J. Uribe-Romo, Catal. Sci. Technol. 2016, 6, 5647-5655.

[71] R. Sun, B. Liu, B.-G. Li and S. Jie, ChemCatChem 2016, 8, 3261-3271.

[72] M. Pintado-Sierra, A. M. Rasero-Almansa, A. Corma, M. Iglesias and F. Sanchez, J. Catal. 2013, 299 137-145.

[73] M. Pourkhosravani, S. Dehghanpour, F. Farzaneh and S. Sohrabi, Reac. Kinet. Mech. Cat. 2017, $122,961-981$.

[74] L. Zhu, X.-Q. Liu, H.-L. Jiang and L.-B. Sun, Chem. Rev. 2017, 117 8129-8176.

[75] R. Kardanpour, S. Tangestaninejad, V. Mirkhani, M. Moghadam, I. Mohammadpoor-Baltork and F. Zadehahmadi, J. Solid State Chem. 2016, 235 145-153.

[76] J. Hou, Y. Luan, J. Tang, A. M. Wensley, M. Yang and Y. Lu, J. Mol. Catal. A: Chem. 2015, 407 5359.

[77] R. Kardanpour, S. Tangestaninejad, V. Mirkhani, M. Moghadam, I. Mohammadpoor-Baltork and F. Zadehahmadi, J. Solid State Chem. 2015, 226 262-272.

[78] M. Kaposi, M. Cokoja, C. H. Hutterer, S. A. Hauser, T. Kaposi, F. Klappenberger, A. Pöthig, J. V. Barth, W. A. Herrmann and F. E. Kühn, Dalton Trans. 2015, 44, 15976-15983.

[79] H. Fei and S. M. Cohen, J. Am. Chem. Soc. 2015, 137, 2191-2194.

[80] H. Fei, J. Shin, Y. S. Meng, M. Adelhardt, J. Sutter, K. Meyer and S. M. Cohen, J. Am. Chem. Soc. 2014, 136, 4965-4973.

[81] K. M. Zwolinski and M. J. Chmielewski, ACS Appl. Mater. Interfaces 2017, 9, 33956-33967.

[82] J. F. Blandez, A. Santiago-Portillo, S. Navalon, M. Gimenez-Marques, M. Alvaro, P. Horcajada and H. Garcia, J. Mol. Catal. A: Chem. 2016, 425, 332-339.

[83] L. Chen, R. Luque and Y. Li, Dalton Trans. 2018, 47, 3663-3668

[84] L. Chen, R. Luque and Y. Li, Chem. Soc. Rev. 2017, 46, 4614-4630.

[85] Z. Guo, C. Xiao, R. V. Maligal-Ganesh, L. Zhou, T. W. Goh, X. Li, D. Tesfagaber, A. Thiel and W. Huang, ACS Catal. 2014, 4, 1340-1348.

[86] X. Li, B. Zhang, L. Tang, T. W. Goh, S. Qi, A. Volkov, Y. Pei, Z. Qi, C.-K. Tsung, L. Stanley and W. Huang, Angew. Chem. Int. Ed. 2017, 56, 16371 -16375.

[87] W. Zhang, G. Lu, C. Cui, Y. Liu, S. Li, W. Yan, C. Xing, Y. R. Chi, Y. Yang and F. Huo, Adv. Mater. 2014, 26, 4056-4060.

[88] K. M. Choi, K. Na, G. A. Somorjai and O. M. Yaghi, J. Am. Chem. Soc. 2015, 137, 7810-7816.

[89] X. Li, Z. Guo, C. Xiao, T. W. Goh, D. Tesfagaber and W. Huang, ACS Catal. 2014, 4, 3490-3497.

[90] X. Li, T. W. Goh, L. Li, C. Xiao, Z. Guo, X. C. Zeng and W. Huang, ACS Catal. 2016, 6, 3461-3468.

[91] I. Luz, C. Rösler, K. Epp, F. X. Llabrés i Xamena and R. A. Fischer, Eur. J. Inorg. Chem. 2015, 39043912. 
[92] Q. Guan, B. Wang, X. Chai, J. Liu, J. Gu and P. Ning, Fuel 2017, 205 130-141.

[93] F. Zhang, S. Zheng, Q. Xiao, Y. Zhong, W. Zhu, A. Lin and M. Samy El-Shall, Green Chem. 2016, 18, 2900-2908.

[94] R. Insyani, D. Verma, S. Min Kim and J. Kim, Green Chem. 2017, 19, 2482-2490.

[95] L. Yin and J. Liebscher, Chem. Rev. 2007, 107 133-173.

[96] A. Dhakshinamoorthy, A. M. Asiri and H. Garcia, Chem. Soc. Rev. 2015, 44, 1922-1947.

[97] R. Kardanpour, S. Tangestaninejad, V. Mirkhani, M. Moghadam, I. Mohammadpoor-Baltork, A. R. Khosropour and F. Zadehahmadi, J. Organometallic Chem. 2014, 761 127-133.

[98] Y. Huang, Z. Zheng, T. Liu, J. Lu, Z. Lin, H. Li and R. Cao, Catal. Commun. 2011, 14, 27-31.

[99] D. Saha, R. Sen, T. Maity and S. Koner, Langmuir 2013, 29 3140-3151.

[100] W. Dong, C. Feng, L. Zhang, N. Shang, S. Gao, C. Wang and Z. Wang, Catal. Lett. 2016, 146, 117125.

[101] M. Pourkhosravani, S. Dehghanpour and F. Farzaneh, Catal. Lett. 2016, 146, 499-508.

[102] J.-C. Wang, Y.-H. Hu, G.-J. Chen and Y.-B. Dong, Chem. Commun. 2016, 52, 13116-13119.

[103] B. Rungtaweevoranit, J. Baek, J. R. Araujo, B. S. Archanjo, K. M. Choi, O. M. Yaghi and G. A. Somorjai, Nano Lett. 2016, 16, 7645-7649.

[104] W. Wang, S. Wang, X. Ma and J. Gong, Chem. Soc. Rev. 2011, 40, 3703-3727.

[105] M. D. Porosoff, X. Yang, J. A. Boscoboinik and J. G. Chen, Angew. Chem. Int. Ed. 2014, 53, 67056709.

[106] S. Moret, P. J. Dyson and G. Laurenczy, Nat. Commun. 2014, 5, 4017.

[107] F. Arena, K. Barbera, G. Italiano, G. Bonura, L. Spadaro and F. Frusteri, J. Catal. 2007, 249, 185194.

[108] K. Leus, P. Concepcion, M. Vandichel, M. Meledina, A. Grirrane, D. Esquivel, S. Turner, D. Poelman, M. Waroquier, V. Van Speybroeck, G. Van Tendeloo, H. Garcia and P. Van Der Voort, RSC Adv. 2015, 5, 22334-22342.

[109] Z. Lin, X. Cai, Y. Fu, W. Zhu and F. Zhang, RSC Adv. 2017, 7, 44082-44088.

[110] N.-Z. Shang, C. Feng, S.-T. Gao and C. Wang, Int. J. Hydrogen Energy 2016, 41, 944-950.

[111] C. Rçsler, S. Dissegna, V. L. Rechac, M. Kauer, P. Guo, S. Turner, K. Ollegott, H. Kobayashi, T. Yamamoto, D. Peeters, Y. Wang, S. Matsumura, G. V. Tendeloo, H. Kitagawa, M. Muhler, F. X. Llabres i Xamena and R. A. Fischer, Chem. Eur. J. 2017, 23, 3583-3594.

[112] M. Wen, K. Mori, Y. Kuwahara and H. Yamashita, ACS Energy Lett. 2017, 2, 1-7.

[113] Z. L. Wang, J. M. Yan, H. L. Wang, Y. Ping and Q. Jiang, J. Mater. Chem. A 2013, 1, 12721-12725.

[114] K. Tedsree, T. Li, S. Jones, C. W. A. Chan, K. M. K. Yu, P. A. J. Bagot, E. A. Marquis, G. D. W. Smith and S. C. E. Tsang, Nat. Nanotechnol. 2011, 6, 302-307.

[115] M. Navlani-García, M. Martis, D. Lozano-Castello, D. Cazorla- Amoros, K. Mori and H. Yamashita, Catal. Sci. Technol. 2015, 5, 364-371.

[116] X. Gu, Z. H. Lu, H. L. Jiang, T. Akita and Q. Xu, J. Am. Chem. Soc. 2011, 133, 11822-11825.

[117] D. Sun, Y. Fu, W. Liu, L. Ye, D. Wang, L. Yang, X. Fu and Z. Li, Chem. Eur. J. 2013, 19, 14279-14285.

[118] A. Dhakshinamoorthy, A. M. Asiri and H. Garcia, Angew. Chem. Int. Ed. 2016, 55, 5414-5445.

[119] X. Deng, Z. Li and H. Garcia, Chem. Eur.J. 2017, 23, 11189-11209

[120] C. K. Prasad Neeli, P. Puthiaraj, Y.-R. Lee, Y.-M. Chung, S.-H. Baeck and W.-S. Ahn, Catal. Today 2018, 303 227-234.

[121] C. S. Hinde, W. R. Webb, B. K. J. Chew, H. R. Tan, W.-H. Zhang, T. S. Andy Hor and R. Raja, Chem. Commun. 2016, 52, 6557-6560.

[122] Q. Yuan, D. Zhang, L. van Haandel, F. Ye, T. Xue, E. J. M. Hensen and Y. Guan, J. Mol. Catal. A: Chem. 2015, 406 58-64.

[123] S.-T. Gao, W. Liu, C. Feng, N.-Z. Shang and C. Wang, Catal. Sci. Technol. 2016, 6, 869-874.

[124] L. Shen, W. Wu, R. Liang, R. Lin and L. Wu, Nanoscale 2013, 5, 9374-9382.

[125] S. Sadeghi, M. Jafarzadeh, A. R. Abbasi and K. Daasbjerg, New J. Chem. 2017, 41, 12014-12027.

[126] Y. Zhang, T. Dai, F. Zhang, J. Zhang, G. Chu and C. Quan, Chinese J. Catal. 2016, 37, 2106-2113.

[127] I. V. Kozhevnikov, Chem. Rev. 1998, 98, 171-198. 
[128] X.-L. Yang, L.-M. Qiao and W.-L. Dai, Micropor. Mesopor. Mater. 2015, 211 73-81.

\section{Table of Contents}




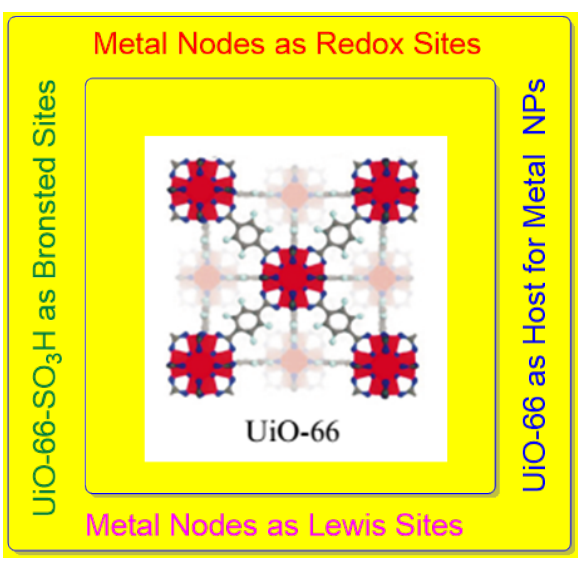

The present review summarizes the use of UiO-66 as Lewis acids with emphasis on the recent developments to generate structural defects, increasing Lewis acidity. Examples of substituted terephthalate as active sites and the synergism between acid and basic sites in close proximity in UiO-66 with substituents at the linker acting are also presented. A section focused on the use of UiO-66 as hosts for metal and metal oxides nanoparticles for various organic transformations including the synthesis of aromatics and fine chemicals. 
Amarajothi Dhakshinamoorthy obtained his Ph.D., degree in 2009 from Madurai Kamaraj University, Tamil Nadu, India. Later, he worked as a postdoctoral researcher with Prof. Hermenegildo Garcia at the Technical University of Valencia for four years. Then, he returned to India and joined as UGC-Assistant Professor in June 2013 at School of Chemistry, Madurai Kamaraj University. His research interests include catalysis by metal-organic frameworks and graphene-related materials. He is the recipient of the Young Scientist Award 2014 for Chemical Sciences by The Academy of Sciences, India. He was also awarded an INSA-DFG international bilateral exchange award to visit Germany in 2015. He has co-authored over one hundred publications with h-index of 44 , three book chapters and one international patent.

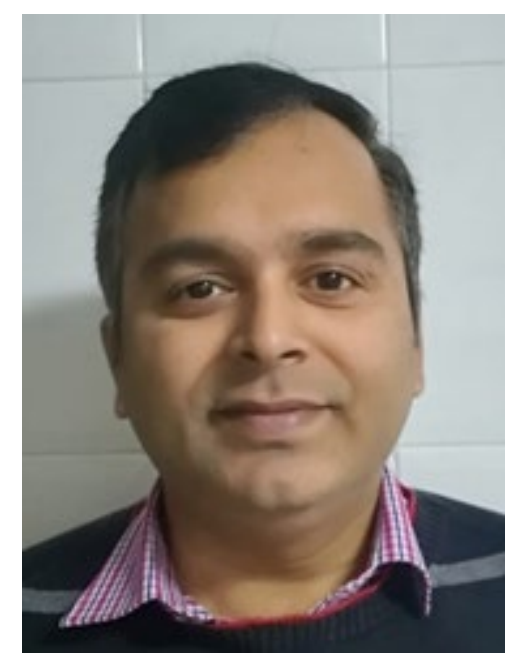

Andrea Santiago was born in Valencia, Spain in 1990. She graduated in Chemical Engineering from Universidad Politécnica de Valencia (2008-2013) and spent five years in the group of Prof. Hermenegildo Garcia as a doctoral student. Recently, she was awarded Ph.D., degree by Universidad Politécnica de Valencia. She is actively working in the synthesis and catalytic applications of Metal Organic Frameworks and she has co-authored fourteen publications. 


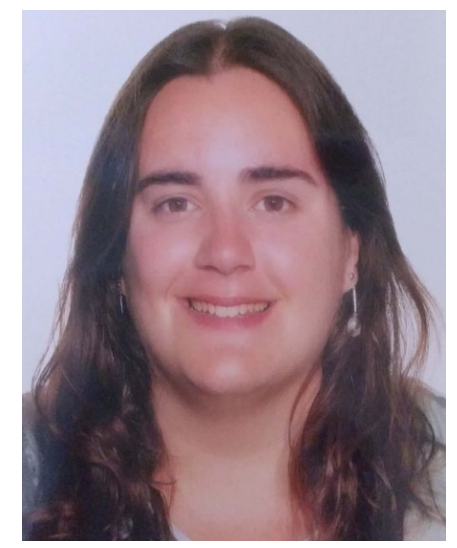

Abdullah M. Asiri received PhD from University of Wales, College of Cardiff, UK in 1995. $\mathrm{He}$ is the Head of the Chemistry Department at King Abdulaziz University since October 2009 and he is the founder and the Director of the Center of Excellence for Advanced Materials Research. He is a Professor of Organic Photochemistry. His research interest covers color chemistry, synthesis of novel photochromic, thermochromic systems, synthesis of novel coloring matters and dyeing of textiles, Materials Chemistry, Nanochemistry and Nanotechnology Polymers, Energy materials and composite materials. He is the Editor-inChief of King Abdulaziz University Journal of Science. He is also a member of the Editorial Board of Pigments and Resin Technology (UK), Designed Monomers \& Polymers. He hold 10 granted USA patents, more than 1242 Publications in international Journals (WoS), ten book Chapters, and 28 Books. Prof. Asiri Won many awards including The custodian of the two holy mosques awards (2017), Khalifa Prize for educations (Best researchers Field) (2018), Shoman Prize (2018). He won the best researcher award in KAU for many successive years.

$\underline{\text { www.aasiri2.kau.edu.sa }}$

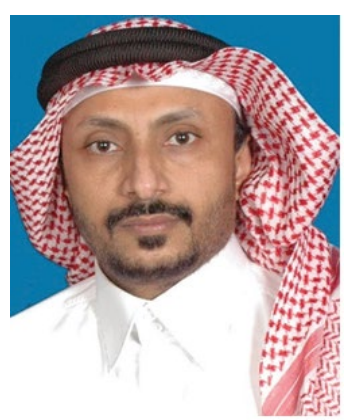


Hermenegildo Garcia is full Professor at the Instituto de Tecnologia Quimica of the Technical University of Valencia, a joint center of the Technical University of Valencia and the Spanish National Research Council and Honorary Adjunct Professor at the Center of Excellence in Advanced Materials Research of King Abdulaziz University. He made a postdoctoral stay at the University of Reading with Professor Andrew Gilbert and several sabbatical leaves in the group of Professor J. C. Scaiano at the University of Ottawa. Prof. Garcia has been active in the field of heterogeneous catalysis working with porous catalysts and nanoparticles, has published over 700 papers and has filed over 25 patents. Prof. Garcia is Doctor Honoris Causa from the University of Bucharest and the recipient of the 2011 Janssen-Cilag award given by the Spanish Royal Society of Chemistry and the 2008 Alpha Gold of the Spanish Society of Glass and Ceramics.

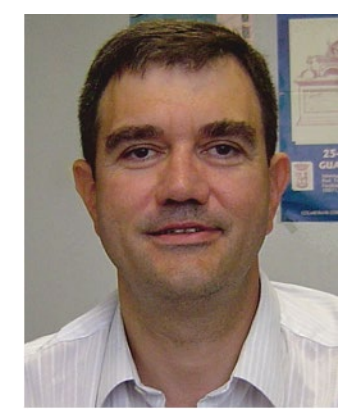

